\title{
Influence of inert gases on the reactive high power pulsed magnetron sputtering process of carbon-nitride thin films
}

Susann Schmidt, Zsolt Czigany, Grzegorz Greczynski, Jens Jensen and Lars Hultman

\section{Linköping University Post Print}

N.B.: When citing this work, cite the original article.

Original Publication:

Susann Schmidt, Zsolt Czigany, Grzegorz Greczynski, Jens Jensen and Lars Hultman, Influence of inert gases on the reactive high power pulsed magnetron sputtering process of carbon-nitride thin films, 2013, Journal of Vacuum Science \& Technology. A. Vacuum, Surfaces, and Films, (31), 1, 011503.

http://dx.doi.org/10.1116/1.4769725

Copyright: American Vacuum Society http://www.avs.org/

Postprint available at: Linköping University Electronic Press http://urn.kb.se/resolve?urn=urn:nbn:se:liu:diva-89755 


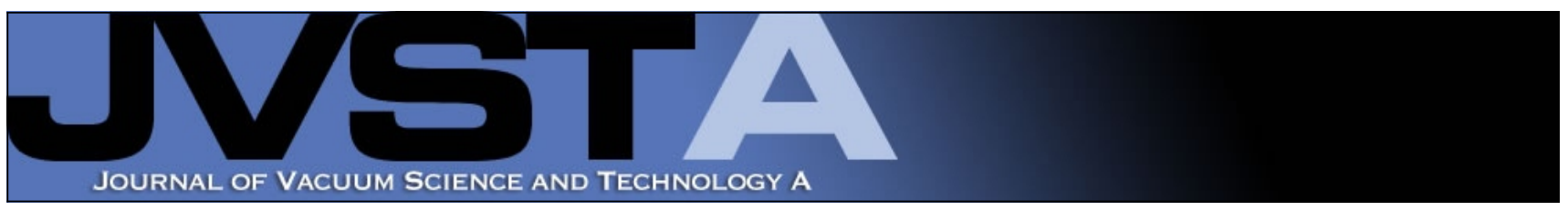

\section{Influence of inert gases on the reactive high power pulsed magnetron sputtering process of carbon-nitride thin films}

Susann Schmidt, Zsolt Czigány, Grzegorz Greczynski, Jens Jensen, and Lars Hultman

Citation: J. Vac. Sci. Technol. A 31, 011503 (2013); doi: 10.1116/1.4769725

View online: http://dx.doi.org/10.1116/1.4769725

View Table of Contents: http://avspublications.org/resource/1/JVTAD6/v31/i1

Published by the AVS: Science \& Technology of Materials, Interfaces, and Processing

\section{Related Articles}

Single Crystalline Oxygen-free Titanium Nitride by XPS

Surf. Sci. Spectra 20, 1 (2013)

The Si3N4/TiN Interface: 4. Si3N4/TiN(001) Grown with a -250 V Substrate Bias and Analyzed In situ using Angle-resolved X-ray Photoelectron Spectroscopy

Surf. Sci. Spectra 19, 62 (2012)

The Si3N4/TiN Interface: 1. TiN(001) Grown and Analyzed In situ using Angle-resolved X-ray Photoelectron

Spectroscopy

Surf. Sci. Spectra 19, 33 (2012)

The Si3N4/TiN Interface: 5. TiN/Si3N4 Grown and Analyzed In situ using Angle-resolved X-ray Photoelectron

Spectroscopy

Surf. Sci. Spectra 19, 72 (2012)

The Si3N4/TiN Interface: 6. Si/TiN(001) Grown and Analyzed In situ using Angle-resolved X-ray Photoelectron Spectroscopy

Surf. Sci. Spectra 19, 82 (2012)

\section{Additional information on J. Vac. Sci. Technol. A}

Journal Homepage: http://avspublications.org/jvsta

Journal Information: http://avspublications.org/jvsta/about/about_the_journal

Top downloads: http://avspublications.org/jvsta/top_20_most_downloaded

Information for Authors: http://avspublications.org/jvsta/authors/information_for_contributors

\section{ADVERTISEMENT}

\section{Instruments for advanced science}
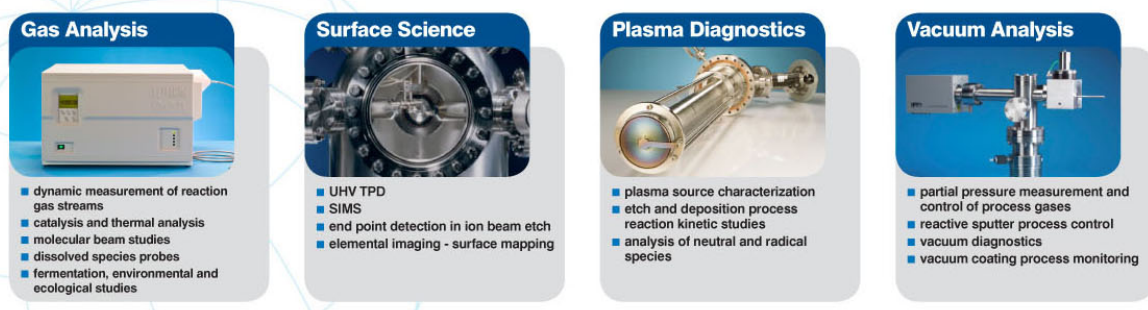

contact Hiden Analytical for further details

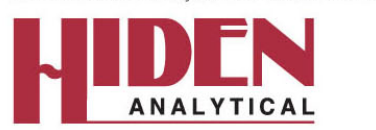

info@hideninc.com

www.HidenAnalytical.com

CLICK to view our product catalogue 


\title{
Influence of inert gases on the reactive high power pulsed magnetron sputtering process of carbon-nitride thin films
}

\author{
Susann Schmidt ${ }^{\mathrm{a})}$ \\ Thin Film Physics Div., Department of Physics (IFM), Linköping University, SE-581 83, Sweden \\ Zsolt Czigány ${ }^{\text {b) }}$ \\ Institute of Technical Physics and Materials Science, Research Centre for Natural Sciences, \\ Hungarian Academy of Sciences, Konkoly Thege Miklós út 29-33. H-1121 Budapest, Hungary \\ Grzegorz Greczynski, ${ }^{\text {) }}$ Jens Jensen, ${ }^{\text {d) }}$ and Lars Hultman ${ }^{\mathrm{e}}$ \\ Thin Film Physics Div., Department of Physics (IFM), Linköping University, SE-581 83, Sweden
}

(Received 13 September 2012; accepted 15 November 2012; published 7 December 2012)

\begin{abstract}
The influence of inert gases $(\mathrm{Ne}, \mathrm{Ar}, \mathrm{Kr})$ on the sputter process of carbon and carbon-nitride $\left(\mathrm{CN}_{\mathrm{x}}\right)$ thin films was studied using reactive high power pulsed magnetron sputtering (HiPIMS). Thin solid films were synthesized in an industrial deposition chamber from a graphite target. The peak target current during HiPIMS processing was found to decrease with increasing inert gas mass. Time averaged and time resolved ion mass spectroscopy showed that the addition of nitrogen, as reactive gas, resulted in less energetic ion species for processes employing $\mathrm{Ne}$, whereas the opposite was noticed when $\mathrm{Ar}$ or $\mathrm{Kr}$ were employed as inert gas. Processes in nonreactive ambient showed generally lower total ion fluxes for the three different inert gases. As soon as $\mathrm{N}_{2}$ was introduced into the process, the deposition rates for $\mathrm{Ne}$ and Ar-containing processes increased significantly. The reactive Kr-process, in contrast, showed slightly lower deposition rates than the nonreactive. The resulting thin films were characterized regarding their bonding and microstructure by $\mathrm{x}$-ray photoelectron spectroscopy and transmission electron microscopy. Reactively deposited $\mathrm{CN}_{\mathrm{x}}$ thin films in $\mathrm{Ar}$ and $\mathrm{Kr}$ ambient exhibited an ordering toward a fullerene-like structure, whereas carbon and $\mathrm{CN}_{\mathrm{x}}$ films deposited in $\mathrm{Ne}$ atmosphere were found to be amorphous. This is attributed to an elevated amount of highly energetic particles observed during ion mass spectrometry and indicated by high peak target currents in Ne-containing processes. These results are discussed with respect to the current understanding of the structural evolution of a-C and $\mathrm{CN}_{\mathrm{x}}$ thin films. (C) 2013 American Vacuum Society. [http://dx.doi.org/10.1116/1.4769725]
\end{abstract}

\section{INTRODUCTION}

The possibility to tailor the microstructure and thus properties of carbon-based thin films for a variety of applications justifies intense research. ${ }^{1-5}$ Especially, diamond-like carbon (DLC) and fullerene-like carbon nitride $\left(\mathrm{FL}-\mathrm{CN}_{\mathrm{x}}\right)$ roused interest due to their different outstanding mechanical properties. DLC possesses superior wear resistance, hardness, chemical inertness, ${ }^{2,6-8}$ and biocompatibility, ${ }^{9}$ whereas FL-CN $\mathrm{C}_{\mathrm{x}}$ exhibits an enormous resiliency (elastic recovery of up to $98 \%$ ), low wear and friction. ${ }^{10,11}$ This combination of properties presents $\mathrm{FL}-\mathrm{CN}_{\mathrm{x}}$ as an ideal material for wear resistant applications. Since the properties of both materials are determined by the energy of film forming species during synthesis, we start by a short review of the current understanding. For DLC, the mechanical properties depend on the variation of the $s p^{3} / s p^{2}-\mathrm{C}$ bonding ratio. An increased amount of $s p^{3}$-bonds leads to high hardness, approaching that of diamond. ${ }^{3,12,13}$ Lifshitz et al. ${ }^{14}$ described the formation of $s p^{3}$ bonds by a local densification and subsequent relaxation of the $\mathrm{C}$ network during high energy ion bombardment

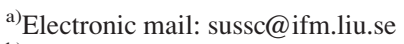

b)Electronic mail: czigany.zsolt@ttk.mta.hu

c)Electronic mail: grzgr@ifm.liu.se

${ }^{\mathrm{d})}$ Electronic mail: jejen@ifm.liu.se

e)Electronic mail: larhu@ifm.liu.se
}

[30-100 eV (Refs. 12, 15, and 16)]. Such deposition conditions are supplied by magnetron sputtering, arc deposition, or ion-beam deposition. In this context, the advantages of high power impulse magnetron sputtering (HiPIMS also known as HPPMS) should be considered as this deposition method generates an increased amount and energy of the ionized target material, due to a high temporal electron density in the HiPIMS plasma. ${ }^{17,18}$ Despite the comparatively high ionization potential $\left(I_{P}=11.26 \mathrm{eV}\right.$, Table I) and low sputter yield ( 0.197 atoms/ion for $500 \mathrm{eV} \mathrm{Ar}$ ions in the C/Ar discharge) of $\mathrm{C}$, an enhanced amount and energy of $\mathrm{C}^{+}$was as well found for the $\mathrm{C}$ discharge in HiPIMS-mode. ${ }^{19}$ Nevertheless, the ionized flux fraction of $\mathrm{C}$ in HiPIMS remains rather low at $4.5 \%{ }^{20}$ Sarakinos et al. showed an increase in the amount of $s p^{3}$-bonds of up to $50 \%$ for DLC films prepared by HiPIMS $^{21}$ compared to DCMS (direct current magnetron sputtering). Petrov et al. ${ }^{22}$ reported higher $\mathrm{C}$ ion energies and, in correlation to this, also increased electron temperatures during magnetron sputtering of $\mathrm{C}$ in $\mathrm{Ne}$ compared to $\mathrm{Ar}$, whereas the inert gas ion-to- $\mathrm{C}$ neutral arrival rates were found to be similar for both inert gases. Aijaz et al. suggested the utilization of $\mathrm{Ne}$ as inert gas while sputtering a graphite target in HiPIMS mode, leading to an increased electron temperature. ${ }^{23}$ The authors claimed a subsequent increase in $\mathrm{C}^{+}$ energy and flux, causing higher amounts of $s p^{3}$-bonds in $\mathrm{C}$ films. The impact of sputter mode and inert gas on the 
TABLE I. Collection of process relevant data for $\mathrm{C} /$ inert gas $/ \mathrm{N}_{2}$-discharges.

\begin{tabular}{|c|c|c|c|c|c|c|}
\hline & \multicolumn{3}{|c|}{ Inert gases } & \multicolumn{2}{|c|}{ Reactive gas species } & \multirow{2}{*}{$\frac{\text { Target material }}{\mathrm{C}}$} \\
\hline & $\mathrm{Ne}$ & $\mathrm{Ar}$ & $\mathrm{Kr}$ & $\mathrm{N}_{2}$ & $\mathrm{~N}$ & \\
\hline 1st ionization energy $(\mathrm{eV}), \mathrm{I}_{\mathrm{P}}$ & 21.56 & 15.75 & 13.99 & 15.6 & 14.53 & 11.26 \\
\hline Total ionization cross section $\left(10^{-17} \mathrm{~cm}^{2}\right)$ at $25 \mathrm{eV}$ & 0.25 (Ref. 58) & 16.5 (Ref. 58) & 19.5 (Ref. 58) & & 1.17 (Ref. 59) & 14.4 (Ref. 59) \\
\hline Metastable excitation energy (eV) (Ref. 43) & 16.6216 .71 & 11.5511 .72 & 9.919 .99 & & & \\
\hline Total sputter yield for $\mathrm{C}$ (atoms/ion) at $100 \mathrm{eV}^{\mathrm{a}}$ & 0.02 & 0.005 & 0.0001 & 0.009 & 0.04 & 0.07 \\
\hline
\end{tabular}

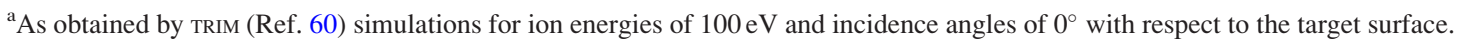

chemical bonding of the $\mathrm{C}$ and $\mathrm{C}$-based films can thus be considered substantial.

Sputtering with different inert gases while keeping the same reactive gas and target material implies changes to plasma and process parameters generally because of differences in collision cross sections, momentum transfer, and ionization/excitation energies. Particularly, differences in sputter yield, electron-impact ionization cross sections, inert gas ionization energies $\left(I_{p}\right)$, as well as metastable excitation energies are of interest (Table I). Apart from the sputter yield, these parameters influence electron impact ionization and Penning ionization (ionization due to metastable inert gas atoms) - the two major ionization mechanisms in the PVD plasma. Moreover, the plasma electron temperature is influenced by $I_{P}$ of the process gasses; increasing $I_{p}$ implicates an increased mean electron energy contributing to ionization. $^{22,24}$ Therefore, the amount and the energy of ions in the plasma are affected as well. Different inert gases also determine the way secondary electrons are created ${ }^{25}$ with respect to relative contributions from inert gas ions, recoils, and electrons. In the case when graphite is sputtered in $\mathrm{Ne}$, electrons and ions contribute to the electron yield to approximately equal parts of $\sim 40 \%$ and $\sim 60 \%$, respectively. If $\mathrm{Kr}$ is used as inert gas, contributions to the electron yield of ions dominate $(\sim 80 \%)$, recoiled atoms play an increased role $(\sim 10 \%)$ and, in this case, a lower contribution for electrons $(\sim 10 \%)$ was calculated. ${ }^{25}$ Adding $\mathrm{N}_{2}$, as reactive gas, to the Ne discharge one of the major metal ionization mechanisms in PVD — the Penning ionization-was found to play a considerable role for the ionization of $\mathrm{N}_{2} \cdot{ }^{26}$ In $\mathrm{Ne} / \mathrm{N}_{2}$ discharges with $\mathrm{N}_{2}$ contents up to $50 \%$ a Penning mixture ${ }^{27}$ is formed. The ability of $\mathrm{Ne}$ to Penning ionize $\mathrm{N}_{2}$ according to $^{26,28}$

$$
\mathrm{Ne}^{*}+\mathrm{N}_{2}^{0} \rightarrow \mathrm{Ne}^{0}+\mathrm{N}_{2}^{+}+\mathrm{e}^{-}
$$

is attributed to the metastable states of $\mathrm{Ne}\left(\mathrm{Ne}^{*}\right)$ at 16.62 and $16.67 \mathrm{eV}$ that exceed the ionization potential of $\mathrm{N}_{2}$ $\left(I_{P}=15.6 \mathrm{eV}\right)$ and $\mathrm{N}\left(I_{P}=14.53 \mathrm{eV}\right)$. In the cathode sheath, the conversion of kinetic energy to vibration/excitation and dissociation of molecular nitrogen may occur in the two steps:

$$
\mathrm{N}_{2}^{+}(\text {fast })+\mathrm{N}_{2}^{0} \rightarrow \mathrm{N}_{2}^{+\nu}(\text { slow })+\mathrm{N}_{2}^{0}
$$

and

$$
\mathrm{N}_{2}^{+\nu} \rightarrow \mathrm{N}^{+}+\mathrm{N}^{0}
$$

where $\nu$ represents vibration excitation energy. The dissociative charge transfer (2) has threshold energy of $\sim 24 \mathrm{eV}^{28}$ Also possible are ionization and dissociation of $\mathrm{N}_{2}$ due to electron impact or the ionization due to charge transfer from inert gas ions. ${ }^{28}$ However, the existence of several metastable states of $\mathrm{N}_{2}$ allows manifold ionization and dissociation pathways. ${ }^{29}$ Generally, for low-pressure discharges the process gas ionization ( $\mathrm{Ne}, \mathrm{Ar}, \mathrm{Kr}, \mathrm{N}_{2}$ ) is likely to be governed by electron impact ionization.

The evolution of the distinct FL-CN $\mathrm{x}_{\mathrm{x}}$ microstructure was first described theoretically by Gueorguiev et al. ${ }^{30}$ and arises due to the incorporation of $\mathrm{N}$ into the $\mathrm{C}$-matrix, causing the formation of pentagon defects and this in turn provokes a bending and cross linking of the graphene sheets. Those bent cross linked graphene sheets give rise to the outstanding mechanical properties of this material. From an experimental point of view, the mechanism behind the structural evolution of $\mathrm{FL}-\mathrm{CN}_{\mathrm{x}}$ - chemical sputtering-was first reported by Hellgren et $a{ }^{4}{ }^{4}$ and later theoretically explained by Schluter et al. ${ }^{31}$ Chemical sputtering is a temperature regulated chemical desorption process taking place at the growth surface procuring structure-defining $\mathrm{C}_{\mathrm{x}} \mathrm{N}_{\mathrm{y}}{ }^{+}$-species $(\mathrm{x}, \mathrm{y} \leq 2)$. Recently, we published a comparative study, in which different HiPIMS and DCMS processes for the deposition of FL$\mathrm{CN}_{\mathrm{x}}$ thin films were evaluated. The study revealed that a mechanism that can be described as pulse assisted chemical sputtering during reactive HiPIMS of a graphite target promotes the structural evolution of $\mathrm{CN}_{\mathrm{x}}$ thin films toward a FL structure and is taking place already at the target. Additionally, operating the graphite target with short, but high power pulses, as it is done in HiPIMS, produces an increased average energy and amount of $\mathrm{C}^{+}$, but also increased amounts of $\mathrm{C}_{\mathrm{x}} \mathrm{N}_{\mathrm{y}}{ }^{+}$-species. ${ }^{19}$

It becomes evident that HiPIMS process and plasma parameters are distinctly different for each of the gases and that a wide process window can be spanned in their utilization. Former DCMS studies on $\mathrm{CN}_{\mathrm{x}}$ thin films presented the substrate temperature $\left(\mathrm{T}_{\mathrm{s}}\right)$, the energy of film-forming ions, and the nitrogen-to-argon flow ratio $\mathrm{f}_{\mathrm{N}_{2} / \mathrm{Ar}}$ as most important growth parameters in order to modify the $\mathrm{CN}_{\mathrm{x}}$ thin film microstructure and thus properties. ${ }^{11} \mathrm{We}$ expect vast possibilities to control and influence $\mathrm{CN}_{\mathrm{x}}$ thin film formation during HiPIMS. The role of different inert gases on reactive HiPIMS deposition of $\mathrm{CN}_{\mathrm{x}}$ films is, however, unexplored. In 
the presented study, we investigate the effect of three different inert gases ( $\mathrm{Ne}, \mathrm{Ar}, \mathrm{Kr}$ ) on HiPIMS process and plasma parameters as well as on the chemical bonding and microstructure of $\mathrm{CN}_{\mathrm{x}}$ thin films. Conclusions on the growth as well as structure-defining mechanisms are drawn from the evaluation of the plasma processes (ion mass-spectrometry, target current waveforms) in combination with thin film characterization [high resolution transmission electron microscopy (HRTEM), selected area electron diffraction (SAED), and x-ray photo electron spectroscopy (XPS)].

\section{EXPERIMENT DETAILS}

Ion mass-spectrometry measurements and film depositions were carried out in an industrial CC800/9 coating system (CemeCon AG, Germany). Plasma characterization and film depositions were made in HiPIMS mode. Our investigations were performed using one rectangular target with an area of $440 \mathrm{~cm}^{2}$. Pure graphite targets (Tokai CARBON Deutschland $\mathrm{GmbH}$ ) were sputtered in $\mathrm{Ne}, \mathrm{Ar}$, or $\mathrm{Kr}$ and additionally in inert gas $/ \mathrm{N}_{2}$ atmosphere at a constant pressure of $400 \mathrm{mPa}$. The amount of $\mathrm{N}_{2}$ in the working gas, defined by

$$
\frac{\mathrm{f}_{\mathrm{N}_{2}}}{\mathrm{f}_{\text {inertgas }}+\mathrm{f}_{\mathrm{N}_{2}}} \cdot 100 \%
$$

where $\mathrm{f}_{\mathrm{N}_{2}}$ and $\mathrm{f}_{\text {inertgas }}$ represent the flow of $\mathrm{N}_{2}$ and inert gas, respectively, ranged between $14 \%$ and $100 \%$. In powerregulated mode a frequency of $300 \mathrm{~Hz}$ was applied. For ion mass spectrometry measurements of Ne-containing processes, an average power of $1800 \mathrm{~W}$ was applied to the cathode, whereas for processes involving $\mathrm{Kr}$ an average power of $1400 \mathrm{~W}$ was used. Reference measurements for both power settings (1400 and $1800 \mathrm{~W}$ ) were conducted in an $\mathrm{Ar}$ containing atmosphere. An average power of $1800 \mathrm{~W}$ was chosen for Ne-containing discharges due to the fact that more stable discharge conditions during ion mass spectroscopy measurements were achieved with this slightly higher average power. The pulse width was kept constant in all processes at $200 \mu \mathrm{s}$. The measurements took place at room temperature. Furthermore, since the mass spectrometer orifice is grounded no additional bias voltage was applied.

IEDFs were measured in a time-averaged and timeresolved mode for the most abundant ionic plasma species, namely $\mathrm{C}^{+}, \mathrm{C}_{2}{ }^{+}, \mathrm{N}^{+}, \mathrm{N}_{2}^{+}, \mathrm{Ne}^{++}, \mathrm{Ne}^{+}, \mathrm{Ar}^{+}, \mathrm{Ar}^{++}, \mathrm{Kr}^{++}$, ${ }^{82} \mathrm{Kr}^{+},{ }^{84} \mathrm{Kr}^{+},{ }^{86} \mathrm{Kr}^{+}, \mathrm{CN}^{+}$, and $\mathrm{C}_{2} \mathrm{~N}_{2}{ }^{+}$. The measurements were performed with a PSM003 unit from Hiden Analytical, UK, operated with a quadrupole mass analyzer sensitive to masses up to $300 \mathrm{amu}$ with a resolution of $0.1 \mathrm{amu}$. In order to allow comparisons, the measurements were carried out with identical global settings (including detector, extractor, and quadrupole voltages and currents) after fine-tuning with regards to mass 12 , assigned to $\mathrm{C}^{+}$. The position of the spectrometer orifice relative to the target with regards to the angle as well as spatial and lateral was comparable to the arrangement of the substrates to the target. A distance of $60 \mathrm{~mm}$ between target and the spectrometer orifice was kept similar for all measurements and corresponds also to the spacing between target and substrate during thin film deposition. Time-averaged data were recorded between $-0.5 \mathrm{eV}$ and $50 \mathrm{eV}$ with step widths of $0.5 \mathrm{eV}$. The dwell time was set to $100 \mathrm{~ms}$, which corresponds to an information depth of at least 30 pulses in each data point. Acquisitions for timeresolved ion mass-spectrometry measurements were triggered by the signal from a Tektronix DPO4054 $500 \mathrm{MHz}$ bandwidth digital oscilloscope. The delay time, related to the onset of the power pulse to the cathode, ranged from $40 \mu$ s up to $280 \mu$ s with an increment of $20 \mu$ s. A total acquisition time of $1 \mathrm{~ms}$ per data point was applied. Timeresolved mass spectrometry was carried out for ion energies ranging between 0 and $30 \mathrm{eV}$ with a resolution of $0.5 \mathrm{eV}$. The ion time-of-flight (TOF) within the mass spectrometer was corrected for presented time-resolved data, with the purpose to show the plasma composition at the spectrometer orifice (substrate surface) rather than at the spectrometers' detector. Therefore, the approach suggested by Bohlmark et $a l .{ }^{32}$ was used. The plasma species and their calculated corresponding TOF are listed in Table II. Naturally, the TOF of ions within the mass spectrometer depends on their initial kinetic energy. However, for kinetic energies below $100 \mathrm{eV}$, the TOF varies not more than $10 \%$. Since this is the case for the applied processes, a mean particle energy of $8 \mathrm{eV}$ was used for all TOF calculations. During ion mass spectrometry measurements the target current and target voltage waveforms were recorded with a Tektronix DPO4054 $500 \mathrm{MHz}$ bandwidth digital oscilloscope.

Thin films were deposited on $\mathrm{Si}(001)$ substrates using an average power of $1400 \mathrm{~W}$ for all inert gases and inert gas $/ \mathrm{N}_{2}$ mixtures. The above presented settings regarding the pulse width and frequency were used as well during deposition. In addition, a pulsed bias voltage $\left(\mathrm{V}_{\mathrm{b}}\right)$ of $-100 \mathrm{~V}$, synchronized with the cathode high voltage pulse, was applied to the substrate table. Two different substrate temperatures $\left(\mathrm{T}_{\mathrm{s}}\right)$ of $110^{\circ} \mathrm{C}$ and at $430^{\circ} \mathrm{C}$ were chosen for the thin film deposition. Thin films deposited at a low substrate temperature of $110^{\circ} \mathrm{C}$ were evaluated regarding their deposition rate $\left(\mathrm{R}_{\mathrm{d}}\right)$ and $\mathrm{N}$ content, in order to allow comparisons with the results gained by plasma characterization. The effect of the inert gases on the structural evolution of the $\mathrm{CN}_{\mathrm{x}}$ films is presented here for samples deposited at $430^{\circ} \mathrm{C}$, since substrate

TABLE II. Measured ion species together with their mass/charge ratio and TOF correction.

\begin{tabular}{lcc}
\hline \hline Ion & $\mathrm{m} / \mathrm{e}$ & TOF correction $(\mu \mathrm{s})$ \\
\hline $\mathrm{C}^{+}$ & 12 & 32 \\
$\mathrm{C}_{2}^{+}$ & 24 & 45 \\
$\mathrm{CN}^{+}$ & 26 & 47 \\
$\mathrm{C}_{2} \mathrm{~N}_{2}^{+}$ & 52 & 67 \\
$\mathrm{Ne}^{+}$ & 20 & 41 \\
$\mathrm{Ne}^{++}$ & 10 & 29 \\
$\mathrm{Ar}^{+}$ & 40 & 59 \\
$\mathrm{Ar}^{++}$ & 20 & 41 \\
${ }^{84} \mathrm{Kr}^{+}$ & 84 & 85 \\
$\mathrm{Kr}^{++}$ & 42 & 60 \\
\hline \hline
\end{tabular}


temperatures above $300{ }^{\circ} \mathrm{C}$ were found to be necessary to form the FL-structure. ${ }^{33,34}$

Deposition rates were determined with cross-sectional scanning electron microcopy (SEM, LEO 1550 Gemini, Zeiss, Germany). The composition of $\mathrm{CN}_{\mathrm{x}}$ films were evaluated using time-of-flight elastic recoil detection analysis (ToF-ERDA) applying an $36 \mathrm{MeV}^{127} \mathrm{I}^{9+}$ ion beam at $22.5^{\circ}$ incidence angle relative to the surface ${ }^{35,36}$ Here, data were stored event by event in list mode and analyzed off-line. Only the data obtained during the first minutes (yielding sufficient statistics) were used.

X-ray photoelectron spectroscopy (XPS) was performed with a Quantum 2000 spectrometer from PHI Physical Electronics, Inc., USA, using a monochromatic $\mathrm{Al}\left(\mathrm{K}_{\alpha}\right) \mathrm{X}$-ray beam $(\mathrm{h} \nu=1486.6 \mathrm{eV})$ and a chamber pressure of less than $1.4 \times 10^{-6} \mathrm{~Pa}$. XPS data of the $\mathrm{C} 1 \mathrm{~s}, \mathrm{~N} 1 \mathrm{~s}$, and O1s regions were collected after the samples were sputter-cleaned for $10 \mathrm{~min}$ with $500 \mathrm{eV} \mathrm{Ar}^{+}$ions. The lowest sputter energy possible was chosen as the $\mathrm{CN}_{\mathrm{x}}$ bonding structure was reported to be easily affected and might also be accompanied by a preferential sputtering of N. ${ }^{37}$ Automatic charge compensation was applied, due to the fact that $\mathrm{CN}_{\mathrm{x}}$ films typically

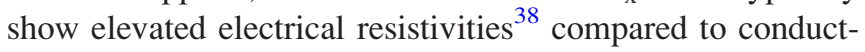
ing materials. Obtained spectra were fitted using Voigt peak shape, with the Lorentzian contribution not exceeding $20 \%$. The full width at half maximum (FWHM) was restricted to $1.7 \mathrm{eV}$ for the main contributions $\mathrm{C} 1$ and $\mathrm{C} 2$ of the N1s core level spectra, whereas the FWHM of the minor contributions C3 and C4 was restricted to $2.0 \mathrm{eV}$. A Shirley-type background was used and all spectra were referenced to the $\mathrm{C}-\mathrm{C}$ $(\mathrm{C}-\mathrm{CH})$ bond at $284.5 \mathrm{eV}$.

Cross-sectional TEM was carried out on cleaved samples. ${ }^{39}$ These samples were examined in a Tecnai G2 TF 20 UT TEM (FEI, The Netherlands). SAED patterns were exposed with a CCD camera in the same instrument and processed with diffraction software. ${ }^{40}$ The degree of structuring (fullerene-like, graphitic or amorphous) was assessed in evaluating peak intensities of the rings at $\sim 3.5 \AA$ and $\sim 2 \AA\left(I_{3.5 A^{\circ}}\right.$ and $\left.I_{2 A^{\circ}}\right)$, extracted from the SAED pattern. The relative peak intensity $\left(\mathrm{R}=\mathrm{I}_{3.5 \AA} / \mathrm{I}_{2} \AA\right.$ ) describes the degree of graphitic short range ordering in $\mathrm{CN}_{\mathrm{x}}$ and C-based materials. $^{41}$

\section{RESULTS AND DISCUSSION}

\section{A. Target current and target voltage waveforms for different inert gases}

In order to investigate the effect of different inert gases on the sputter process for the deposition of a-C and $\mathrm{CN}_{\mathrm{x}}$ thin films, the target current $\mathrm{I}(\mathrm{t})$ and target voltage $\mathrm{U}(\mathrm{t})$ wave forms are evaluated first. In the case of industrial HiPIMS processing operated on large-area cathodes, the shape of the target current and target voltage traces depends to large extent on the size of the capacitor bank of the pulsing unit. The resulting voltage pulse is far from an ideal, rectangular form, and often exhibits a sudden drop in amplitude with pulse time. Examples of such behavior can be seen in Fig. 1, where current and voltage waveforms for processes in pure

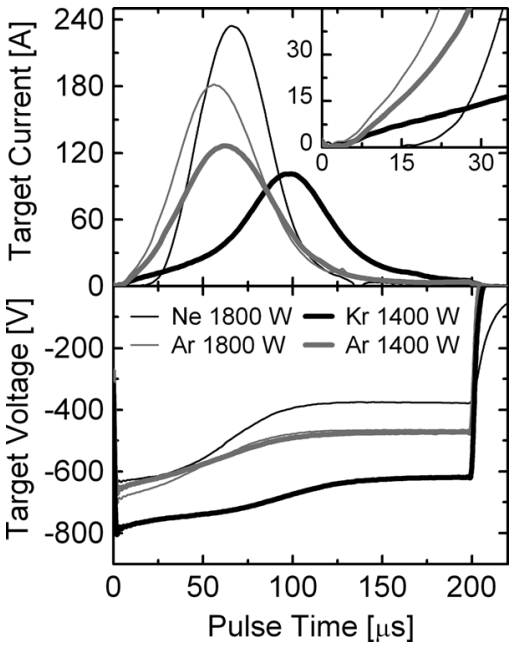

FIG. 1. Target current and target voltage waveforms for HiPIMS processes comparing different inert gases; $\mathrm{Ne}(\mathrm{Pav}=1800 \mathrm{~W}$, black thin line $)$ and the corresponding Ar process ( $\mathrm{Pav}=1800 \mathrm{~W}$, gray thin line) as well as $\mathrm{Kr}$ $(\mathrm{Pav}=1400 \mathrm{~W}$, black bold line) with corresponding Ar process $(\mathrm{Pav}=1400 \mathrm{~W}$, gray bold line). The inset presents a magnification of the first $35 \mu \mathrm{s}$ of $\mathrm{I}(\mathrm{t})$ and depicts the delay in the raise of the target current.

$\mathrm{Ne}$ [cf. black thin line, $\left.\left.\mathrm{P}_{\mathrm{Tav}}=1800 \mathrm{~W}\right)\right]$ and pure $\mathrm{Kr}$ [cf. black bold line, $\left.\mathrm{P}_{\mathrm{Tav}}=1400 \mathrm{~W}\right)$ ] are presented. As reference, the corresponding $I(t)$ and $U(t)$ characteristics of equivalent processes (the same frequency, pressure, process temperature, and pulse duration) employing Ar for both power settings are additionally included in Fig. 1. Evident is the high peak target current ( $\hat{\mathrm{I}}$ ) of $\sim 245 \mathrm{~A}$ as the graphite target is sputtered in pure $\mathrm{Ne}$ atmosphere in comparison to $\hat{\mathrm{I}} \sim 180 \mathrm{~A}$ for the process in pure $\mathrm{Ar}$ atmosphere. In contrast to this is the $\hat{\mathrm{I}}$ for the discharge in $\mathrm{Kr}$, as it rises to $\sim 100 \mathrm{~A}$ at an average power of $1400 \mathrm{~W}$ and is thus compared to $\hat{\mathrm{I}} \sim 126 \mathrm{~A}$ of the Ar discharge at $1400 \mathrm{~W}$ (cf. gray bold line Fig. 1) rather low.

The discharge current comprises ion and electron current. Increased $\hat{\mathrm{I}}$ values indicate in a first approximation elevated amounts of charged species that form in the vicinity of the target as different noble gases are used for the sputter process. Factors that influence the over-all amount of charged sputtered species and consequently contributing to $\hat{\mathrm{I}}$ are as follows:

(i) The sputter yield, as more particles are sputtered, the probability for ionization is enhanced. The sputter yield of carbon increases for the used noble gases in the sequence $\mathrm{Kr}$, Ar, Ne (Table I).

(ii) The first ionization potential $I_{P}$ of the inert gas; an increased $I_{P}$ implies elevated electron temperatures, ${ }^{22,24}$ contributing to ionization and thus, $\hat{\mathrm{I}}$. The ionization potential increases with decreasing inert gas atomic number (Table I).

(iii) The total ionization cross section for electron energies below $50 \mathrm{eV}$ increase in the sequence $\mathrm{Ne}, \mathrm{Ar}$, and $\mathrm{Kr}$, (Table I). ${ }^{42}$ Here, it should be taken into account that electron energies are possibly considerably higher for $\mathrm{Ne}$ processes $^{23}$ and decrease with increasing atomic number of the inert gas. Thus, differences in ionization cross sections may not be as crucial. 
(iv) The excitation energies of the metastable energy levels for the three inert gases increase with decreasing inert gas atomic number [Table I (Ref. 43)], whereas the excitation energies for $\operatorname{Ar}(11.55$ and $11.72 \mathrm{eV})$ are just above the first ionization potential of $\mathrm{C}$ $(11.26 \mathrm{eV})$. Therefore, it is reasonable to conclude that Penning excitation and ionization occurs only as the graphite target is sputtered in $\mathrm{Ar}$ and $\mathrm{Ne}$ atmosphere.

(v) The secondary electron emission yield $\left(\gamma_{S E}\right)^{33}$ is considered as well, as it merely depends on $I_{p}$ of the used inert gas in the case the graphite target is sputtered in metallic mode.In order to estimate $\gamma_{S E}$, the empirical equation ${ }^{44}$

$$
\gamma_{S E}=0.032\left(0.78 \mathrm{I}_{\mathrm{P}}-2 \varphi\right)
$$

is valid for HiPIMS processes where particle energies are below $100 \mathrm{eV}$. In Eq. (4), $I_{P}$ resembles the ionization potential of the impinging particles (sputter gas) on the target surface and $\varphi$ the work function of the target material. A three times higher $\gamma_{S E}$ was calculated for the $\mathrm{C} / \mathrm{Ne}$ discharge compared to the $\mathrm{C} / \mathrm{Ar}$ discharge. In case the graphite target is sputtered in $\mathrm{Kr}, \gamma_{S E}$ yielded $30 \%$ of the value for the $\mathrm{C} / \mathrm{Ar}$ discharge. This is mirrored in the peak target current of the $\mathrm{C}$ discharge for the three different inert gases (Fig. 1).

Another remarkable feature is the delay in the onset of the target current pulse (cf. inset in Fig. 1). It is attributed to a number of process parameters such as gas pressure ${ }^{45}$ and target material, ${ }^{46}$ and the process gas composition. ${ }^{47}$ In the presented study, the time dependence of the electrical breakdown (time lag until the target current rises) was observed for different inert gases as well as for different reactive process gas mixtures and is demonstrated in Figs. 1 (inset) and 2(a) and 2(b). Discharges in pure Ar and $\mathrm{Kr}$ show a delay of $6 \mu \mathrm{s}$, whereas the electrical breakdown for $\mathrm{Ne}$ was observed after $22 \mu$ s (inset, Fig. 1). Due to the comparatively high $I_{P}$ and high metastable excitation energies of $\mathrm{Ne}$, the energy loss of fast electrons is more substantial during the exciting and ionization of noble gas atoms, than for $\mathrm{Kr}$ and $\mathrm{Ar}$.

Discharges in pure $\mathrm{N}_{2}$ atmosphere yield an electrical breakdown delay of $9 \mu \mathrm{s}$ and $15 \mu$ s for processes with an average power of 1800 and $1400 \mathrm{~W}$, respectively. Hala et al. ${ }^{40}$ investigated the $\mathrm{I}(\mathrm{t})$ characteristics of $\mathrm{Cr}$ in a reactive $\mathrm{Ar} / \mathrm{N}_{2}$ atmosphere thoroughly. They conclude that the delayed rise of the current is an indication of a delayed gas breakdown due to energy loss of electrons by excitation and dissociation of $\mathrm{N}_{2}$ (electron quenching), since molecular nitrogen has several vibrational and rotational excitation levels that are accessible for energy absorption. However, for reactive carbon discharges involving $\mathrm{N}_{2}$, apart from electron quenching, rather complex sputter mechanisms occur at the target surface and in the vicinity of the target (i.e., chemical desorption processes, excitation and dissociation of nitrogen, and $\mathrm{C}_{\mathrm{x}} \mathrm{N}_{\mathrm{y}}$ molecules). Additionally, not only the properties of the sputter gas are considered to be changed, but also those of the graphite target surface. Therefore, the onset delay of the current pulse in the case of $\mathrm{N}_{2}$ and inert gas $/ \mathrm{N}_{2}$ mixtures may have more than one explanation.

In Figs. 2(a) and 2(b), the current wave forms for reactive processes employing $\mathrm{N}_{2}$ in different $\mathrm{N}_{2} /$ inert gas [ for $\mathrm{N}_{2} / \mathrm{Ne}$,

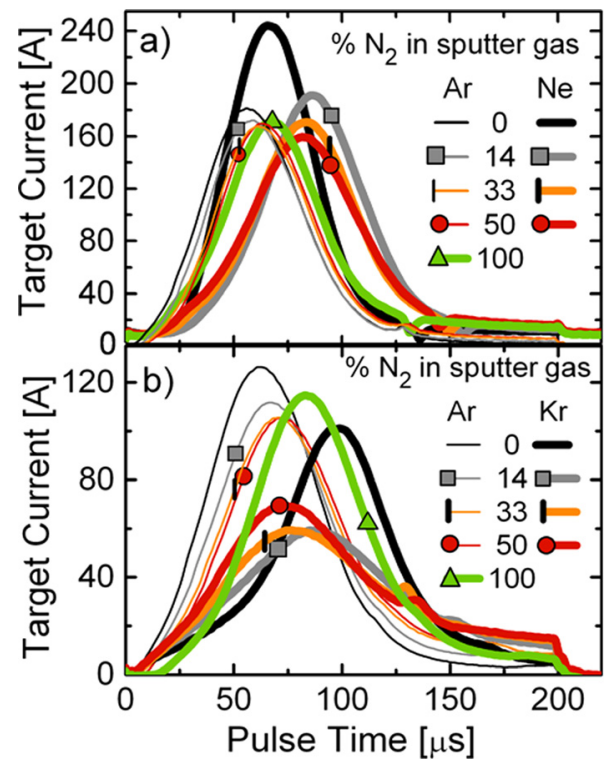

FIG. 2. (Color online) (a), (b) Target current waveforms for reactive HiPIMS processes comparing different $\mathrm{N}_{2}$ contents in the inert gases; (a) $\mathrm{I}(\mathrm{t}$ ) for discharges carried out at $\mathrm{P}_{\mathrm{av}}=1800 \mathrm{~W}$ in $\mathrm{Ne} / \mathrm{N}_{2}$ (bold lines) and in $\mathrm{Ar} / \mathrm{N}_{2}$ (thin lines); (b) $\mathrm{I}\left(\mathrm{t}\right.$ ) for discharges carried out at $\mathrm{P}_{\mathrm{av}}=1400 \mathrm{~W}$ in $\mathrm{Kr} / \mathrm{N}_{2}$ (bold lines) and in $\mathrm{Ar} / \mathrm{N}_{2}$ (thin lines).

$\mathrm{N}_{2} / \mathrm{Ar}$, cf. Fig. 2(a) and $\mathrm{N}_{2} / \mathrm{Ar}, \mathrm{N}_{2} / \mathrm{Kr}$ cf. Fig. 2(b)] mixtures are presented. For reactive processes in $\mathrm{Ar}$ or $\mathrm{Ne}$ [thin and bold lines, respectively, Fig. 2(a)], Î has a minimum as the process is carried out in $\sim 50 \% \mathrm{~N}_{2}$ with values of 166 and $160 \mathrm{~A}$ for $\mathrm{Ar}$ and $\mathrm{Ne}$, respectively. The addition of more $\mathrm{N}_{2}$ to the process gas mixture results in a slight increase of $\hat{I}$ to $170 \mathrm{~A}$ as the graphite target is sputtered in pure $\mathrm{N}_{2}$. This accounts for $70 \%$ of the $\hat{\mathrm{I}}$ when pure $\mathrm{Ne}$ is used and is mainly attributed to differences in $\gamma_{S E}$ as the sputter gas chemistry (different $I_{P}$ of the inert gas/reactive gas mix), but additionally also the work function of the target changes. With the introduction of $\mathrm{N}_{2}$ in the HiPIMS sputter process, the target surface chemistry changes, since dangling $\mathrm{C}$ bonds become passivated by nitrogen and a $\mathrm{C}-\mathrm{N}$ surface layer builds up eventually. The acting mechanisms were investigated and explained in detail for the $\mathrm{C} / \mathrm{Ar} / \mathrm{N}_{2}$ system in Ref. 17 and are assumed to apply for the $\mathrm{C} / \mathrm{Kr} / \mathrm{N}_{2}$ and $\mathrm{C} / \mathrm{Ne} /$ $\mathrm{N}_{2}$ sputter processes as well. Apart from differences in $\gamma_{S E}$, electron-quenching effects may contribute to the decreased $\hat{\mathrm{I}}$ values when $\mathrm{N}_{2}$ is introduced into the reactive HiPIMS process, which were observed for the $\mathrm{Ar}, \mathrm{Ne}$, and $\mathrm{Kr}$ discharges. This quenching effect reduces the probability of electron impact ionization, since electrons lose their energy by excitation of $\mathrm{N}_{2}{ }^{47,48}$

The temporal evolution of Î is distinct; as it shifts toward the pulse end with the introduction of $\mathrm{N}_{2}$ into the Ne discharge. A further increase of $\mathrm{N}_{2}$ in the plasma $(>14 \%)$ causes the peak target current to appear early until it eventually emerges at the same pulse time $(66 \mu \mathrm{s})$ similar to when the process is carried out in pure $\mathrm{N}_{2}$ compared to the process in pure Ne. As graphite is sputtered in $\mathrm{Kr}$ [cf. Fig. 2(b)] mixtures, the opposite is recorded; the target current shows its maximum $(\sim 100 \mathrm{~A})$ in the middle of the pulse (at $\sim 101 \mu \mathrm{s})$. Here, an increase of the nitrogen content in the sputter gas 
causes the target current to peak gradually earlier during the pulse. The temporal evolution observed in the $I(t)$ waveforms shown in Figs. 2(a) and 2(b) does not only depend on the time delay required for the current to rise (electrical breakdown). If corrected for this time delay, the instant the target current peaks still depends on the applied sputter gas as well as average power. In this context, the ionization and excitation mechanisms of $\mathrm{N}_{2}, \mathrm{Kr}, \mathrm{Ar}, \mathrm{Ne}$, and $\mathrm{C}$ are important. Also, the rather complex sputter mechanisms, including next to physical sputtering also temperature dependent chemical desorption processes of $\mathrm{C}_{\mathrm{x}} \mathrm{N}_{\mathrm{y}}$ species from the changed target surface ${ }^{19}$ should be considered.

\section{B. Effects of inert gases on the ion composition of the $\mathrm{C} / \mathrm{N}_{2} /$ inert gas HiPIMS discharge}

Two main components are usually observed in timeaveraged IEDFs recorded for HiPIMS processes; a low-energy portion that mirrors thermalized ions and a high-energy tail. This high-energy tail comprises three main components: the probability function of electron impact ionization, the probability function for collisions between target ions and inert gas neutrals, and the energy transmission function of the mass spectrometer. ${ }^{49}$ Essentially, these components are observed in the present experiments; however, their fractions vary to a large extent in $\mathrm{C}$ plasmas of different inert gases.

Figures 3(a)-3(m) shows IEDFs of the most abundant species arriving at the substrate/orifice, recorded for discharges of graphite in different $\mathrm{N}_{2} / \mathrm{Ne}$ mixtures [Figs. 3(a)-3(f)] and corresponding processes employing Ar [Figs. 3(g)-3(m)] instead of Ne. Most prominent are the IEDFs of $\mathrm{C}^{+}$and $\mathrm{Ne}^{+}$ [Figs. 3(a) and 3(b)] obtained for $0 \% \mathrm{~N}_{2}$ (black lines) $14 \%$ $\mathrm{N}_{2}$ (gray lines) in the sputter gas. In both cases, a broad energy distribution of target and gas ions is evident. This is in contrast to the IEDFs obtained in reactive sputter mode employing $\geq 33 \% \mathrm{~N}_{2}$. A further increase of the reactive gas content causes the high-energy tails in the IEDFs of $\mathrm{C}^{+}, \mathrm{Ne}^{+}$, and $\mathrm{N}^{+}$[Figs. 3(a), 3(b), and 3(f)] to move constantly toward lower energies, which is in contrast to the respective Ar processes [Figs. 3(g), 3(h), and 3(m)]. Here, IEDFs of $\mathrm{C}^{+}, \mathrm{Ar}^{+}$, and $\mathrm{N}^{+}$broaden slightly with the addition of reactive gas although not to the same extent. In fact, IEDFs of discharges involving $\mathrm{Ne}$ are more affected by the addition of $\mathrm{N}_{2}$ than those for discharges involving Ar. This can be attributed to differences in nature of $\mathrm{Ar}$ and $\mathrm{Ne}$ with respect to $\mathrm{N}_{2}$ and the effects of $I_{p}$ on the discharge as discussed above.

Striking is the comparison of $\mathrm{N}_{2}{ }^{+}$and $\mathrm{N}^{+}$IEDF's for the $\mathrm{Ne}$ discharge with $14 \%$ of $\mathrm{N}_{2}$ [gray lines, Figs. 2(c) and 2(f)]; only a small quantity of $\mathrm{N}_{2}{ }^{+}$ions at low energies $(\sim 2.5 \mathrm{eV})$ was recorded, whereas a comparatively large amount of $\mathrm{N}^{+}$ ions with the high-energy tail peaking at $\sim 23 \mathrm{eV}$ was measured for the same process. This indicates enhanced ionization and dissociation mechanisms according to reactions (1) and (2) for $\mathrm{N}_{2}$ in the $\mathrm{Ne} / \mathrm{N}_{2}$ mixtures containing $\sim 14 \% \mathrm{~N}_{2}$. Itagaki et al. correlated the electron temperature and density with the dissociation rate of $\mathrm{N}_{2}$ in an ECR (electron cyclotron resonance) plasma and found for both parameters increased rates. ${ }^{50}$ This in combination with increased plasma

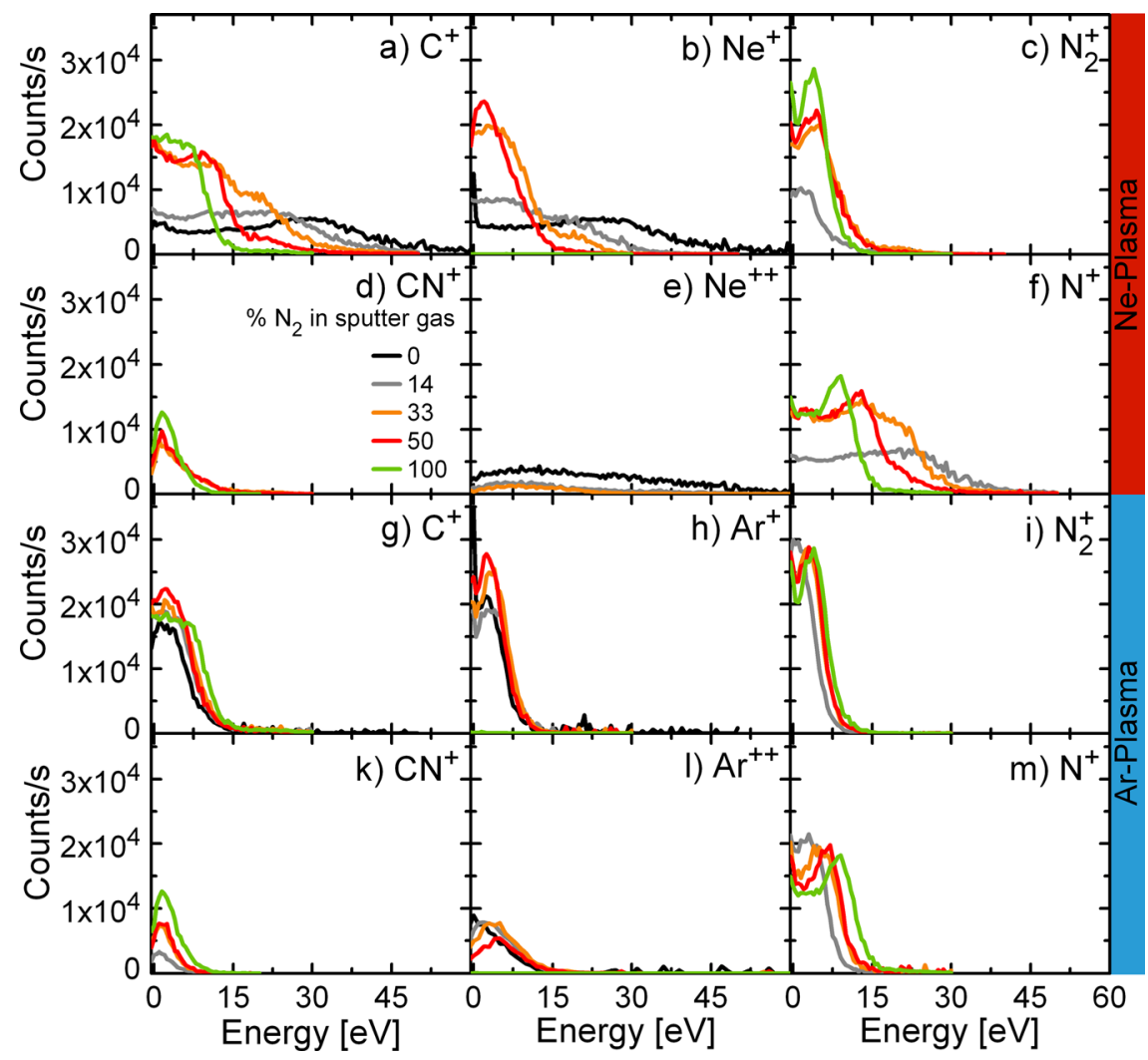

FIg. 3. (Color online) (a)-(m) Time-averaged IEDFs of the most abundant precursor species recorded for HiPIMS discharges at $\mathrm{P}_{\mathrm{av}}=1800 \mathrm{~W}$ in Ne and Ne/ $\mathrm{N}_{2}[(\mathrm{a})-(\mathrm{f})]$ as well as $\mathrm{Ar}$ and $\mathrm{Ar} / \mathrm{N}_{2}[(\mathrm{~g})-(\mathrm{m})]$ of graphite. 
temperatures due to the comparatively high $I_{P}$ of Ne supports the assumption of Penning ionized $\mathrm{N}_{2}$ due to $\mathrm{Ne}$, undergoing a subsequent dissociative charge transfer [cf. reactions (1) and (2)].

Apart from this, IEDFs for $\mathrm{CN}^{+}$and $\mathrm{N}_{2}^{+}$of the $\mathrm{Ne}$ and the Ar plasma do not vary much in energy, merely the amount of ions increases with the increase of $\mathrm{N}_{2}$. Doubly charged $\mathrm{Ne}$ ions [Fig. 3(e)] show a broad distribution and low intensity but were only observed for processes up to $33 \%$ of $\mathrm{N}_{2}$ in the sputter gas, whereas $\mathrm{Ar}^{++}$ions [Fig. 3(1)] were recorded at lower energies peaking at a maximum of $5 \mathrm{eV}$ for all presented Ar-containing processes. Due to the short distance of $60 \mathrm{~mm}$ between the target and the mass spectrometers orifice, the lowered collision probability in the Ne discharge and a relatively high average power of $1800 \mathrm{~W}$, significant amounts of thermalized species were only observed for $\mathrm{Ar}^{+}$ions.

Figures 4(a)-4(f) present the comparison of IEDFs obtained from the most abundant precursor species of $\mathrm{C}$ discharges in $\mathrm{Kr} / \mathrm{N}_{2}$ and $\mathrm{Ar} / \mathrm{N}_{2}$ ambient for comparable process settings. Generally, IEDFs recorded for discharges carried out in $\mathrm{Kr}$-containing atmosphere exhibit narrower energy distributions than the equivalent $\mathrm{Ar}$ processes. The $\mathrm{C}^{+}$ signals [Fig. 4(a)] reside at comparable energies $(\sim 1.5 \mathrm{eV})$ as the $\mathrm{N}_{2}$ content in the sputter gas increases and approaches $50 \% \mathrm{~N}_{2}$ in the sputter gas. The process in pure $\mathrm{N}_{2}$ atmosphere yields a broadening of the $\mathrm{C}^{+}$energy distribution peaking at $\sim 3 \mathrm{eV}$. The respective Ar processes [Fig. 4(g)] yield $\mathrm{C}^{+}$energy distributions that are hardly affected by increasing $\mathrm{N}_{2}$ contents. Here, the IEDF values peak between 1.5 and $3.5 \mathrm{eV}$.

Examples for IEDFs of $\mathrm{Kr}$-isotopes ${ }^{84} \mathrm{Kr}^{+}$and ${ }^{83} \mathrm{Kr}^{+}$are presented in Fig. 4(b) and 4(e), respectively, since the qualitative comparison of their shape can be used to verify the measurements. The distributions of both species show similar features, as should be the case, since both species origin from the same source (inert gas), and hardly vary in mass or dimension. The IEDFs of ${ }^{84} \mathrm{Kr}^{+}$and ${ }^{83} \mathrm{Kr}^{+}$are very narrow and consist of mainly thermalized ions with little dependence on the $\mathrm{N}_{2}$ content in the sputter gas. Moreover, the relative abundance of the $\mathrm{Kr}$-isotopes ${ }^{82} \mathrm{Kr}^{+},{ }^{83} \mathrm{Kr}^{+},{ }^{84} \mathrm{Kr}^{+}$, and ${ }^{86} \mathrm{Kr}^{+}$(not shown here) was extracted from the corresponding distributions to yield in $13.8,16.9,54.2$, and $15.0 \%$, respectively. This is in fair agreement with data published by Yoon and Glab, ${ }^{51}$ for the respective abundances 11.6, 11.5, 57, and $17.3 \% .{ }^{78} \mathrm{Kr}^{+}$and ${ }^{80} \mathrm{Kr}^{+}$were omitted in our measurements and their evaluation, due to their low abundance of $0.35 \%$ and $2.25 \%$, respectively. ${ }^{51}$ In contrast to $\mathrm{Kr}^{+}$, broader distributions are obtained for $\mathrm{Ar}^{+}$under comparable process conditions in Ar-containing discharges. Here, the peak value of the high-energy tail moves from 5 to $2 \mathrm{eV}$ as soon as $\mathrm{N}_{2}$ is added to the process and remains there with the further increase of reactive gas [Fig. 4(h)]. It is noted that the difference in average power (1400 and $1800 \mathrm{~W})$ for Ar-containing processes has no significant affect on ion energies of the recorded species. In all $\mathrm{Kr}$-containing processes, doubly charged $\mathrm{Kr}$ ions (not shown here) were present and yielded $\sim 50 \%$ of the energy compared to $\mathrm{Ar}^{++}$[Fig. 4(1)].

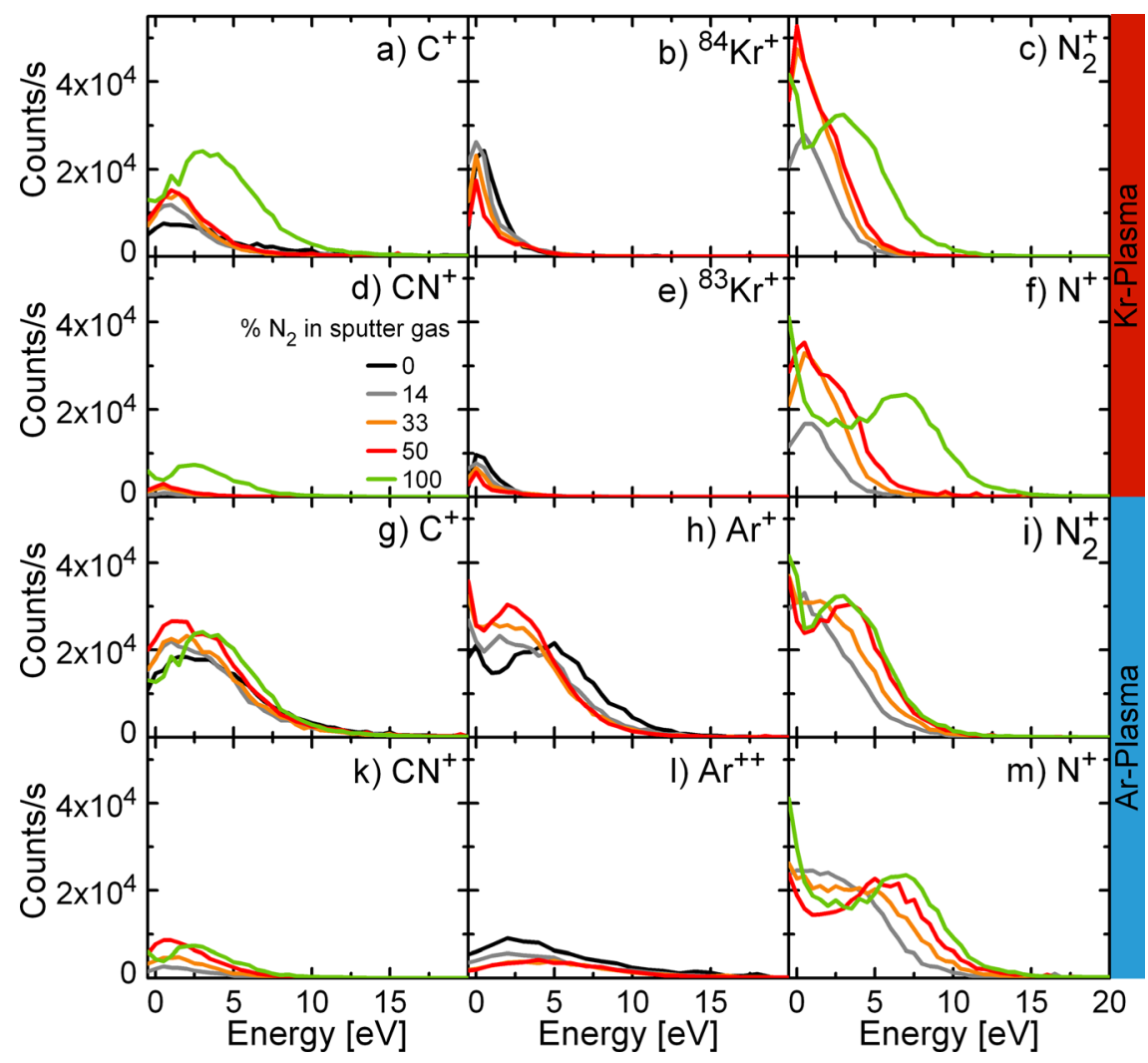

FIg. 4. (Color online) (a)-(m) Time-averaged IEDFs of the most abundant precursor species recorded for HiPIMS discharges at $\mathrm{P}_{\mathrm{av}}=1400 \mathrm{~W}$ in $\mathrm{Kr}$ and $\mathrm{Kr} / \mathrm{N}_{2}$ $[(\mathrm{a})-(\mathrm{f})]$ as well as $\mathrm{Ar}$ and $\mathrm{Ar} / \mathrm{N}_{2}[(\mathrm{~g})-(\mathrm{m})]$ of graphite. 
Distributions of $\mathrm{N}_{2}{ }^{+}$and $\mathrm{N}^{+}$, recorded for $\mathrm{Kr}$ and $\mathrm{Ar}-$ containing processes at $1400 \mathrm{~W}$ [Figs. 4(c), 4(f), 4(i), and $4(\mathrm{~m})$, respectively], exhibit higher energies as the $\mathrm{N}_{2}$ content in the sputter gas increases. This was also observed in IEDFs of $\mathrm{N}_{2}{ }^{+}$and $\mathrm{N}^{+}$for the discharge of $\mathrm{C} / \mathrm{Ar} / \mathrm{N}_{2}$ at $1800 \mathrm{~W}$. Similar processes in Ne-containing atmosphere showed the opposite effect; the mean energy of $\mathrm{N}^{+}$decreased as more $\mathrm{N}_{2}$ is introduced. This demonstrates the effect of the Penning mixture as $\mathrm{C}$ is sputtered in $\mathrm{Ne}$ with small amounts of $\mathrm{N}_{2}$. Moreover, for $\mathrm{Kr} / \mathrm{N}_{2}$-containing processes with more than $14 \% \mathrm{~N}_{2}$ significant portions of thermalized $\mathrm{N}_{2}{ }^{+}$and $\mathrm{N}^{+}$were recorded, owing to the higher collision cross sections in the $\mathrm{Kr} / \mathrm{N}_{2}$ plasma.

Figures 5(a) and 5(b) present the comparison on the ion flux of the most abundant precursor species of sputter processes using $\mathrm{Ne}$ and $\mathrm{Ar}$, respectively, as a function of the nitrogen content. Here, data from time-averaged mass spectrometry were integrated over the entire energy range. For the $\mathrm{C}$ process in pure $\mathrm{Ne}$, the ion fluxes of $\mathrm{C}^{+}$and $\mathrm{Ne}^{+}$ions are equal, showing a relative flux of $\sim 35 \%$. $\mathrm{C}^{++}$and $\mathrm{Ne}^{++}$ species were recorded with a relative abundance of $17 \%$ and $12 \%$, respectively. This high amount of doubly charged species is a consequence of the high energetic $\mathrm{C} / \mathrm{Ne}$ discharge, providing for the necessary energy to create such species. The comparison to the correspondent $\mathrm{C} / \mathrm{Ar}$ process shows reduced ion fluxes for $\mathrm{C}^{+}$and $\mathrm{Ar}^{+}$. However, with respect to the $\mathrm{C} / \mathrm{Ne}$ process the relative $\mathrm{C}^{+}$and $\mathrm{Ar}^{+}$ion fluxes are higher ( $\sim 41 \%$ and $\sim 48 \%$, respectively), owing to the absence of $\mathrm{C}^{++}$and the low relative flux of $\mathrm{Ar}^{++}(\sim 10 \%)$.

With the introduction of $\mathrm{N}_{2}$ to the processes, the total ion fluxes rise instantly for both inert gases with peak values at $33 \%$ of $\mathrm{N}_{2}$ in the sputter gas (Fig. 5). The total ion flux is significantly higher when $\mathrm{Ne}$ is employed. For the Ne/ $\mathrm{N}_{2}$ plasma between $14 \% \mathrm{~N}_{2}$ and $50 \% \mathrm{~N}_{2}$ in the sputter gas, mainly $\mathrm{C}^{+}, \mathrm{N}^{+}$and to a lower extent $\mathrm{Ne}^{+}$as well as $\mathrm{N}_{2}^{+}$is observed. The comparably high flux of $\mathrm{C}^{+}$is a consequence of the increased sputter yield for $\mathrm{C}$ in $\mathrm{Ne}$ in combination with elevated amounts and energies of electrons as well as

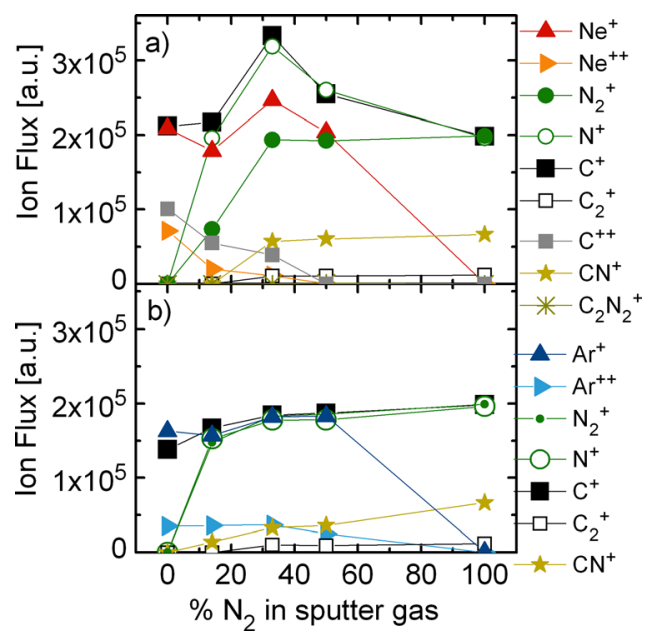

FIG. 5. (Color online) (a), (b) Ion fluxes in dependence of the nitrogen content in the inert gas for (a) $\mathrm{Ne}$ and (b) Ar-containing processes extracted from time averaged IEDFs of the corresponding processes. high metastable energy levels of Ne, providing an increased probability of ionization events due to electron impact and Penning ionization. This stands in contrast to the $\operatorname{Ar} / \mathrm{N}_{2}$ plasma, where $\mathrm{C}^{+}, \mathrm{N}^{+}, \mathrm{N}_{2}{ }^{+}$, and $\mathrm{Ar}^{+}$exist to equal amounts.

The doubly charged ion fluxes decrease continuously until they are hardly quantifiable when the process gas exceeds $33 \% \mathrm{~N}_{2}$ in either $\mathrm{Ne}$ or Ar. In return the fluxes of $\mathrm{C}_{\mathrm{x}} \mathrm{N}_{\mathrm{y}}$ species $(\mathrm{x}, \mathrm{y} \leq 2)$ grow in magnitude. The $\mathrm{CN}^{+}$flux rises constantly with the $\mathrm{N}_{2}$ content for Ar-containing discharges, but in Ne discharges it is first quantified at $33 \%$ of $\mathrm{N}_{2} \cdot \mathrm{C}_{\mathrm{x}} \mathrm{N}_{\mathrm{y}}$ species are a result of chemical sputtering (thermal desorption) at the target and substrate. For $\mathrm{Ne} / \mathrm{N}_{2}$-containing discharges $\left(\mathrm{N}_{2}<33 \%\right)$, their formation may be hindered or $\mathrm{C}_{\mathrm{x}} \mathrm{N}_{\mathrm{y}}$ species are dissociated by particles with high energies.

As the amount of inert gas decreases due to the increase of the $\mathrm{N}_{2}$ fraction in the sputter gas the ion flux of the inert gases do not follow the expected trend; the flux of $\mathrm{Ne}^{+}$peaks at $33 \%$ and shows at $50 \%$ of $\mathrm{N}_{2}$ a comparable value to the process as no reactive gas is used. A similar course is observed for the $\mathrm{Ar}^{+}$flux with peak values at 33\% and 50\% of $\mathrm{N}_{2}$ in the sputter gas. This can be attributed to the overall increased amount of ions in the reactive process causing an additional ionization of the working gas. The comparatively high flux of $\mathrm{N}^{+}$ions is remarkable for the process in $\mathrm{Ne} / \mathrm{N}_{2}$ atmosphere at $14 \% \mathrm{~N}_{2}$. With further addition of $\mathrm{N}_{2}$ to the $\mathrm{Ne}$ process, the $\mathrm{N}^{+} / \mathrm{N}_{2}{ }^{+}$ion flux rate decreases continuously (2.7 at $14 \% \mathrm{~N}_{2}, 1.6$ at $33 \% \mathrm{~N}_{2}, 1.4$ at $50 \% \mathrm{~N}_{2}$, and 0.98 at $100 \% \mathrm{~N}_{2}$ in the sputter gas), attributed to a lowered dissociation and ionization of $\mathrm{N}_{2}$ as a consequence of decreasing amounts of Ne. Electron impact ionization and dissociation are likely to play a considerable role, too, because of the high $\gamma_{S E}$ and electron temperature (high $I_{P}$ ) in discharges where $\mathrm{Ne}$ is the major part of the process gas. The above presented results suggest that the effects of both described ionization and dissociation pathways are significant as long as $\mathrm{Ne}$ is the major process gas $\left(\mathrm{N}_{2}\right.$-contents $\left.<50 \%\right)$, which is supported by results from Avelar-Batista et al. investigating $\mathrm{Ne}-\mathrm{N}_{2}$ interactions in DC discharges by optical emission spectroscopy. ${ }^{26}$ Moreover, in the case Ar is used, the relative flux of $\mathrm{N}^{+}$and $\mathrm{N}_{2}{ }^{+}$is equal and does not change significantly over the entire range of reactive sputter processes $\left(14 \% \mathrm{~N}_{2}\right.$ to $100 \% \mathrm{~N}_{2}$ ).

The comparison on the ion flux of the most abundant plasma precursors for $\mathrm{Kr}$ and $\mathrm{Ar}$ containing processes is presented in Figs. 6(a) and 6(b), respectively. Here, a lower average power $(1400 \mathrm{~W})$ was applied, than for the comparison of Ne versus $\operatorname{Ar}(1800 \mathrm{~W})$, since most stable process conditions were achieved by these settings for the different inert gases in the described process setup. The lower average power is mirrored in the $\mathrm{Ar} / \mathrm{N}_{2}$ plasma by slightly reduced $\mathrm{C}^{+}$and $\mathrm{CN}^{+}$ion fluxes, whereas $\mathrm{Ar}^{+}, \mathrm{N}_{2}^{+}$, and $\mathrm{N}^{+}$ [Fig. 6(b)] are comparable to corresponding fluxes extracted for the $\mathrm{Ar} / \mathrm{N}_{2}$ plasma at $1800 \mathrm{~W}$ [Fig. 5(b)]. Therefore, the total, relative, and the sum of the ion fluxes for Ar processes employing $1400 \mathrm{~W}$ or $1800 \mathrm{~W}$ do not differ significantly. As can be drawn from Fig. 6(a), the total $\mathrm{C}^{+}$and $\mathrm{Kr}^{+}$fluxes are strikingly low in the $\mathrm{Kr} / \mathrm{N}_{2}$ plasma. As the $\mathrm{N}_{2}$ content rises, 


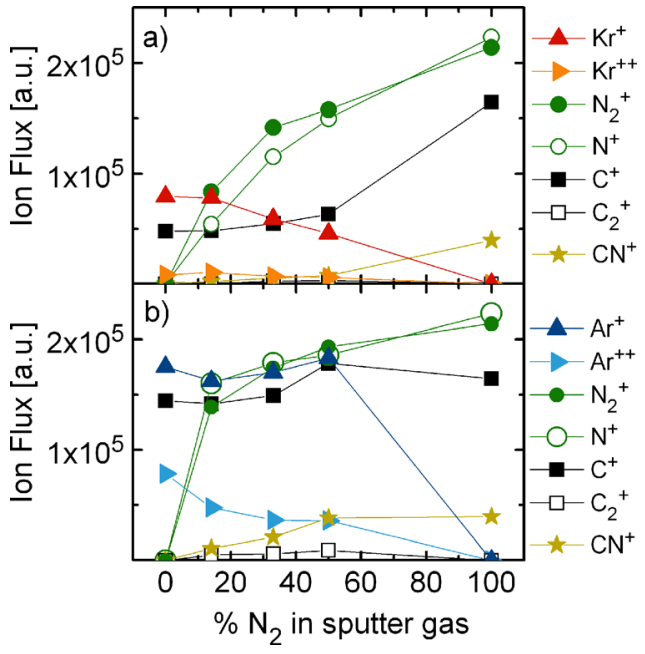

FIG. 6. (Color online) (a), (b) Ion fluxes in dependence of the nitrogen content in the inert gas for (a) $\mathrm{Kr}$ and (b) Ar-containing processes extracted from time averaged IEDFs of the corresponding processes.

the $\mathrm{Kr}^{+}$signal falls steadily, which is not observed for Arand Ne-containing processes up to $50 \% \mathrm{~N}_{2}$ in the plasma. Possible causes may be the higher electron impact ionization cross section for $\mathrm{N}_{2}$ implicating a lack of electrons with sufficient energy to ionize Kr. This would arise due to the low $I_{P}$ of $\mathrm{Kr}$, leading to a reduced $\gamma_{\mathrm{SE}}$ and electrons of decreased energy. In addition, the electron quenching due to the presence of $\mathrm{N}_{2}$ should be considered in this respect. Moreover, it implies that ions and electrons generated by the ionization of the rising $\mathrm{N}_{2}$ content cannot contribute significantly to the ionization of $\mathrm{Kr}$. At the same time, the $\mathrm{C}^{+}$flux increases slightly and maximizes as the discharge is carried out in pure $\mathrm{N}_{2}$, owing to higher sputter yields of $\mathrm{C}$ in nitrogen. As the $\mathrm{N}_{2}$ content in the sputter gas exceeds $14 \%$ the $\mathrm{C} / \mathrm{Kr} / \mathrm{N}_{2}$ plasma is already dominated by $\mathrm{N}_{2}{ }^{+}$and $\mathrm{N}^{+}$. Fluxes of both species increase steeply with the $\mathrm{N}_{2}$ content in the process gas. This is attributed to the low amount of inert gas and target ions due to above discussed reduced ionization rates in the Kr-containing plasma. Larger $\mathrm{C}_{\mathrm{x}} \mathrm{N}_{\mathrm{y}}(\mathrm{x}, \mathrm{y} \leq 2)$ species most probably originating from the target ${ }^{19,52}$ increase in fraction with the $\mathrm{N}_{2}$ content in the sputter gas. For processes employing $\mathrm{Kr}$, their abundance is lower than for processes carried out in Ar-containing atmosphere.

Time-resolved ion mass spectrometry data of the $\mathrm{C}$ discharges in $\mathrm{Ne}$ and $\mathrm{Ne} / 14 \% \mathrm{~N}_{2}(1800 \mathrm{~W}), \mathrm{Ar}$ and $\mathrm{Ar} / 14 \%$ $\mathrm{N}_{2}(1800 \mathrm{~W})$, as well as $\mathrm{Kr}$ and $\mathrm{Kr} / 14 \% \mathrm{~N}_{2}(1400 \mathrm{~W})$ are presented in Figs. 7(a)-7(f). Here, time-resolved energy scans were integrated over the whole energy range and presented in dependence of the pulse time. Data were corrected for the TOF within the mass spectrometer as described in Sec. II (Table II). The arrival of the ions at the orifice with regards to the pulse onset depends to a great extent on the target-orifice distance. However, the temporal sequence in which the different ion species appear is based on their energy, size, and origin (target or working gas). Timeresolved ion mass spectrometry data are shown for discharge in pure $\mathrm{Ne}$, Ar, and $\mathrm{Kr}$ in Figs. 7(a), 7(c), and 7(e), respectively. Obvious is the rather simultaneous arrival of ionic species related to the $\mathrm{C} / \mathrm{Ne}$ discharge [Fig. 7(a)], as the bulk of ions in the Ne-containing discharge appears right at the beginning of the pulse, indicating particles with high energies. The main portion of ions related to the Ar-containing discharge [Fig. 7(c)] emerges at $\sim 25 \mu$ s, and in case $\mathrm{Kr}$ [Fig. 7(e)] is used, the appearance is further delayed to $\sim 50 \mu$ s after pulse onset. For discharges in either Ar or $\mathrm{Kr}$, the working gas ions $\left(\mathrm{Ar}^{+}\right.$and $\left.\mathrm{Kr}^{+}\right)$are observed well before $(\sim 20 \mu \mathrm{s}) \mathrm{C}^{+}$ions, and last doubly charged inert gas ions appear. This temporal sequence of working gas and target ions is typically observed for HiPIMS discharges and correlates with the $\mathrm{I}(\mathrm{t})$ characteristics of the process. ${ }^{19,47,53}$

The addition of $14 \%$ reactive gas has a strong impact on the temporal evolution on the sputter processes of graphite in $\mathrm{Ne}$ and $\mathrm{Kr}$; Figs. 7(b) and 7(f) suggest a delayed arrival (at $\sim 60 \mu$ s pulse time) for the main portion of ions related to the $\mathrm{Ne}$ and $\mathrm{Kr}$ processes. In the $\mathrm{C} / \mathrm{Ne} / \mathrm{N}_{2}$ discharge, the first ions arriving at the mass spectrometers orifice are $\mathrm{N}^{+}$and

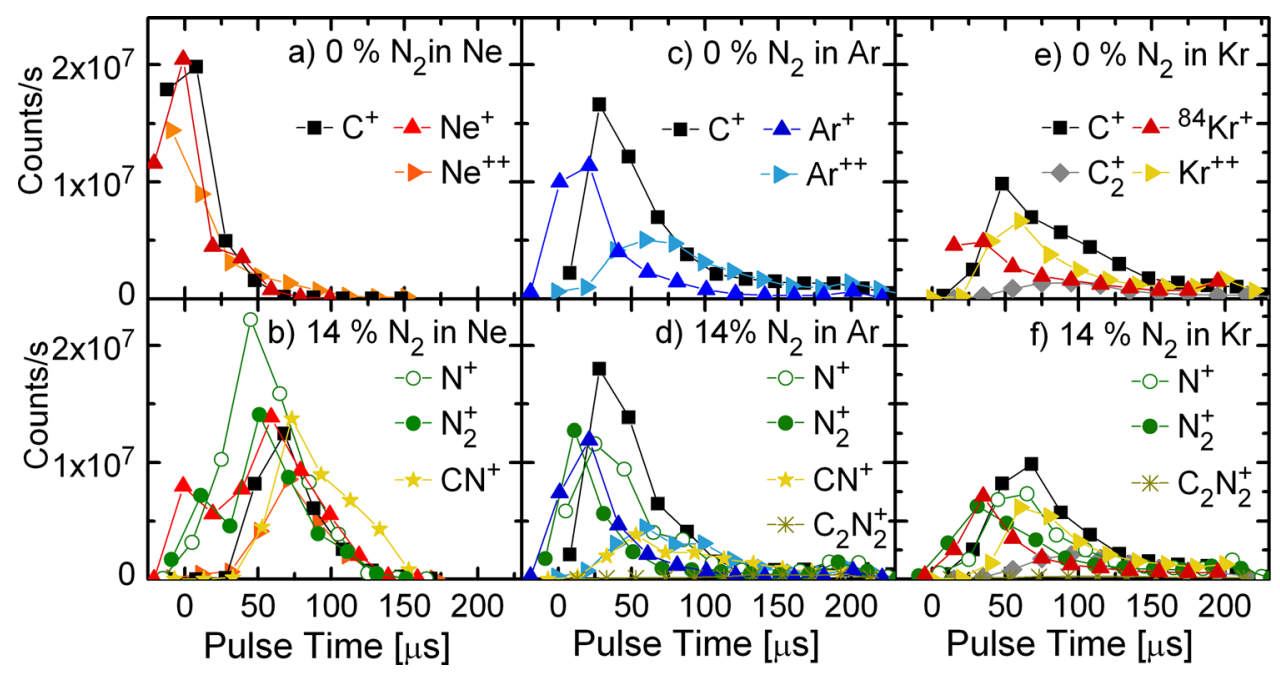

FIg. 7. (Color online) (a)-(f) Total ion count rate vs. pulse time (corresponding to the onset of the pulse) for the graphite discharge in (a) Ne, (b) Ne/14\%, (c) $\mathrm{Ar}$, (d) $\mathrm{Ar} / 14 \% \mathrm{~N}_{2}$, (e) $\mathrm{Kr}$, and (f) $\mathrm{Kr} / 14 \% \mathrm{~N}_{2}$. Each data point represents IEDFs recorded during 1 ms and integrated over the entire energy range. 
$\mathrm{N}_{2}^{+}(\sim 50 \mu \mathrm{s})$, closely followed by $\mathrm{Ne}^{+}(\sim 60 \mu \mathrm{s})$ and last are $\mathrm{C}^{+}(\sim 70 \mu \mathrm{s}), \mathrm{Ne}^{++}(\sim 71 \mu \mathrm{s})$, together with $\mathrm{CN}^{+}(\sim 73 \mu \mathrm{s})$. The first species observed in the reactive discharge employing $\mathrm{Ar}$ and $\mathrm{N}_{2}$ are $\mathrm{N}_{2}{ }^{+}(\sim 10 \mu \mathrm{s})$ and $\mathrm{Ar}^{+}(\sim 20 \mu \mathrm{s})$ followed by $\mathrm{N}^{+}(\sim 25 \mu \mathrm{s})$ together with $\mathrm{C}^{+}(\sim 30 \mu \mathrm{s})$ and, again the last species arriving are $\mathrm{CN}^{+}$and $\mathrm{Ar}^{++}$(both $\sim 60 \mu \mathrm{s}$ ). The temporal evolution of the $\mathrm{Kr}$ discharge is much more defined in the arrival of working gas ions $\left(\mathrm{Kr}^{+}\right.$isotopes and $\mathrm{N}_{2}{ }^{+}$at $\sim 35 \mu \mathrm{s})$ and ions supposedly originating from the target $\left(\mathrm{C}^{+}\right.$, $\mathrm{N}^{+}$, and $\mathrm{Kr}^{++}$at $\sim 70 \mu \mathrm{s}$ ) and somewhat later after $\sim 90 \mu \mathrm{s}$ $\mathrm{C}_{2}{ }^{+}$. An enhanced representation of the temporal evolution of plasma species of a $\mathrm{C} / \mathrm{Ar} / \mathrm{N}_{2}$ discharge could be extracted from time-resolved ion mass spectroscopy with an increased target-orifice distance of $210 \mathrm{~mm} .{ }^{19}$ Here, the time windows for working gas ions and ions originating from the target become more distinct with the applied distance. However, in order to get a deeper understanding of the particles origin time-averaged IEDFs should be considered additionally, as the qualitative comparison of the shape might contain valuable information. In the case of $\mathrm{Ne}$, for example, IEDFs of $\mathrm{N}^{+}$and $\mathrm{C}^{+}$show the similar qualitative features. The corresponding time-resolved data show that a considerable portion of $\mathrm{N}^{+}$is arriving together with $\mathrm{C}^{+}$. It is thus reasonable to assume that this fraction of $\mathrm{N}^{+}$originates from a nitrogen passivated graphite target surface.

\section{Impact of inert gases on a-C and $\mathrm{CN}_{\mathbf{x}}$ film growth and microstructure}

As was demonstrated in Sec. III B, processes employing different inert gases differ to a great extent in particle energy, the amount of $\mathrm{C}^{+}, \mathrm{N}^{+}, \mathrm{N}_{2}{ }^{+}$, and inert gas ions as well as in the amount of so-called structure-defining $\mathrm{C}_{\mathrm{x}} \mathrm{N}_{\mathrm{y}}{ }^{+}$ species. This implies effects on the film growth and the microstructure of a-C and $\mathrm{CN}_{\mathrm{x}}$ thin films, which will be addressed in this section.

In Fig. 8, the deposition rates of a-C (solid square) and $\mathrm{CN}_{\mathrm{x}}$ (open triangle) are shown for the three different inert gases as obtained from the ratio of the film thickness (by cross-sectional SEM) and the deposition time. Evident are the low deposition rates for films deposited with HiPIMS in pure $\mathrm{Ne}$ and $\mathrm{Ne} / 14 \% \mathrm{~N}_{2}$, compared to those of Ar. Considering the comparatively high sputter yield of $\mathrm{C}$ in $\mathrm{Ne}$, the deposition rates should be higher. However, the high ion count rates for the corresponding $\mathrm{Ne}$ processes suggest that more material is lost by their back attraction. ${ }^{54}$ Moreover, $\mathrm{C}^{+}, \mathrm{Ne}^{+}$, and $\mathrm{N}^{+}$energies in Ne-containing processes [cf. Figs. 3(a), 3(b), and 3(f), gray and black lines, 14\% and $0 \%$ $\mathrm{N}_{2}$ in the sputter gas] are 10-12 times higher than those recorded for Ar. This, in combination with the bias voltage of $-100 \mathrm{~V}$, which was set for all depositions, increases the energy of ions impinging on the substrate further. Therefore, the physical resputter processes at the substrate may occur to much higher extent in case the graphite target is sputtered in $\mathrm{Ne}$ and $\mathrm{Ne} / 14 \% \mathrm{~N}_{2}$ atmosphere compared to the corresponding Ar- and $\mathrm{Kr}$-sputter processes. The deposition carried out in pure $\mathrm{Kr}$ atmosphere showed a similar rate as the corresponding Ar process. Also, the reactive process in $\mathrm{Kr} / \mathrm{N}_{2}$

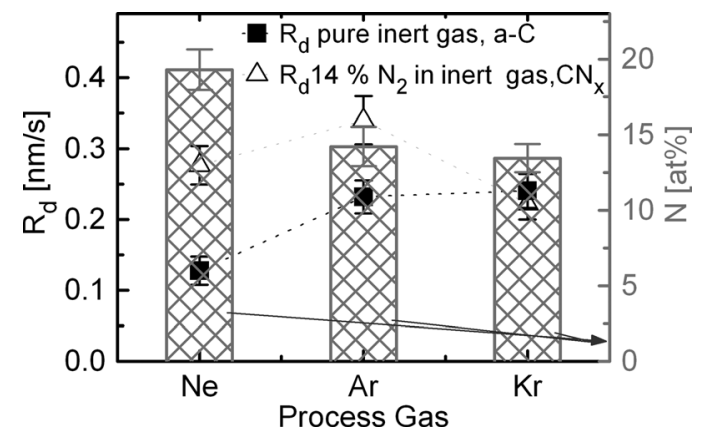

FIG. 8. Deposition rates $\left(\mathrm{R}_{\mathrm{d}}\right)$ for nonreactive (filled squares) and reactive processes (14\% $\mathrm{N}_{2}$, open triangles) as obtained from the ratio of film thickness and deposition time as well as the $\mathrm{N}$ nitrogen contents ([N]) of $\mathrm{CN}_{\mathrm{x}}$ thin films deposited at a substrate temperature of $110^{\circ} \mathrm{C}$ in $\mathrm{Ne}, \mathrm{Ar}$, and $\mathrm{Kr}$.

yielded a comparatively low deposition rate. This agrees with similar $\mathrm{C}$ sputter yields of $\mathrm{C}$ in $\mathrm{Kr}$ and $\mathrm{Ar}^{55}$

Moreover, Fig. 8 presents the nitrogen content of the $\mathrm{CN}_{\mathrm{x}}$ films for $\mathrm{Ne}, \mathrm{Ar}$, and $\mathrm{Kr}$ as obtained by ERDA. Obvious is the elevated $\mathrm{N}$ content of $\sim 19$ at. $\%$ in the $\mathrm{CN}_{\mathrm{x}}$ film deposited in $\mathrm{Ne} / \mathrm{N}_{2}$ atmosphere. The combination of efficient $\mathrm{N}_{2}$ dissociation and ionization, and $\mathrm{N}$ species of high energy lead to an increased amount of incorporated N. The effect of high particle energies was also observed in ERDA depth profiles (not shown here), as a three times broader substrate/thin film interface was found for the $\mathrm{CN}_{\mathrm{x}}$ thin film deposited in $\mathrm{Ne}$ compared to that produced in $\mathrm{Kr}$-containing atmosphere. This intermixing of the materials is caused by high particle energies. The $\mathrm{CN}_{\mathrm{x}}$ deposition in $\mathrm{Kr}$ yields $\sim 13$ at. $\% \mathrm{~N}$ in the films. This is considered to be a consequence of the reduced $\mathrm{N}_{2}$ dissociation and ionization in the $\mathrm{Kr} / 14 \% \quad \mathrm{~N}_{2}$ plasma. Here, lowered total and relative contents of $\mathrm{CN}^{+}$ ions as well as $\mathrm{N}^{+}$ions were found, indicating decreased amounts of $\mathrm{C}_{\mathrm{x}} \mathrm{N}_{\mathrm{y}}$ species and dissociated $\mathrm{N}_{2}$ in the plasma. These species are understood to be key components for the incorporation of nitrogen into the film.

Figure 9 comprises N1s core level photoelectron spectra of $\mathrm{CN}_{\mathrm{x}}$ thin films deposited at $430{ }^{\circ} \mathrm{C}$ with $14 \% \mathrm{~N}_{2}$ in $\mathrm{Kr}, \mathrm{Ar}$, or Ne. A maximum number of four contributions (C1-C4) were fitted into the N1s spectra. The main contributions, C1 ( $400.5 \mathrm{eV}$ ) and C2 (398.1-398.6 eV), are assigned to nitrogen substitutional bonded in a 3 -fold coordinated C-network (e.g., $\mathrm{N}$ bonded into a $\mathrm{sp}^{2}$-coordinated carbon plane) and a $\mathrm{sp}^{2}$-hybridized nitrogen bonded with two bonds to the C-network (pyridine-like), respectively. ${ }^{56,57}$ The bonding configuration associated with $\mathrm{C} 2$ arises next to defects or at the periphery of the graphene sheets, breaking their continuity. As indicated in Fig. 9, the $\mathrm{C} 1 / \mathrm{C} 2$ increases with decreasing amount of incorporated $\mathrm{N}$ in the film (values for $[\mathrm{N}]$ at $430{ }^{\circ} \mathrm{C}$ are given in Fig. 9) and increasing inert gas mass. $\mathrm{C} 1 /$ $\mathrm{C} 2$ is greater than one for Ar- and $\mathrm{Kr}$-containing processes. The structural arrangement of thin films is correlated to the $\mathrm{C} 1 / \mathrm{C} 2$ ratio. ${ }^{56}$ Increased $\mathrm{C} 1 / \mathrm{C} 2$ ratios indicate a pronounced fullerene-like structural evolution, since $\mathrm{C} 1(\sim 400.5 \mathrm{eV})$ is attributed to $\mathrm{N}$ substitutionally bonded in extended carbon sheets, while $\mathrm{C} 2(\sim 398.2 \mathrm{eV})$ is attributed to $\mathrm{N}$ bonded along edges and defects. ${ }^{56,57}$ For $\mathrm{CN}_{\mathrm{x}}$ thin films deposited in either 


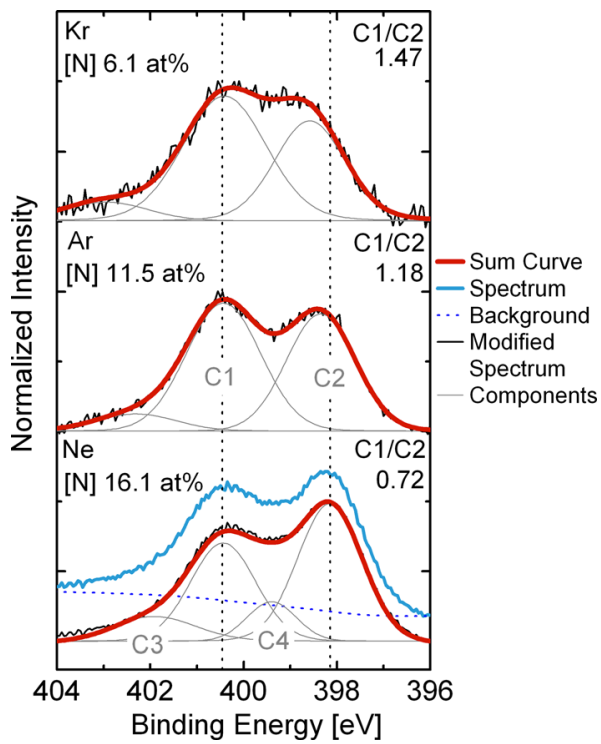

FIG. 9. (Color online) XPS N1s spectra of $\mathrm{CN}_{\mathrm{x}}$ thin films deposited using reactive HiPIMS and a substrate temperature of $430{ }^{\circ} \mathrm{C}$ in $\mathrm{Ne}, \mathrm{Ar}$, and $\mathrm{Kr}$ containing $14 \% \mathrm{~N}_{2}$. The peak deconvolution, the $\mathrm{N}$ content in the $\mathrm{CN}_{\mathrm{x}}$ thin films, and the $\mathrm{C} 1 / \mathrm{C} 2$ ratios of the corresponding films are indicated.

$\mathrm{Kr}$ - or Ar-containing atmosphere, the $\mathrm{C} 1 / \mathrm{C} 2$ ratios are higher than 1 , indicating that both $\mathrm{CN}_{\mathrm{x}}$ films exhibit a FL-structure. This is conceivable as both processes showed low ion energies (cf. Sec. III B) preserving structure-defining $\mathrm{C}_{\mathrm{x}} \mathrm{N}_{\mathrm{y}}$-species $(x, y \leq 2)$ in the plasma, which in turn promote the chemical desorption processes at the substrate. Especially, the $\mathrm{Kr}$ process was governed by low energy ions, which is mirrored in the comparably high $\mathrm{C} 1 / \mathrm{C} 2$ ratio of 1.47 . In contrast to the high $\mathrm{C} 1 / \mathrm{C} 2$ ratio observed for $\mathrm{CN}_{\mathrm{x}}$ obtained in $\mathrm{Kr}$-containing atmosphere, $\mathrm{C} 1$ and $\mathrm{C} 2$ appear broadened, additionally, $\mathrm{C} 2$ shifts toward higher binding energies. Both usually imply amorphous structures and were observed in thin films deposited at temperatures below $300{ }^{\circ} \mathrm{C} .{ }^{56}$

The deposition of $\mathrm{CN}_{\mathrm{x}}$ thin films in Ne-containing atmosphere yields $\mathrm{C} 1 / \mathrm{C} 2<1$, indicating an amorphous structure with frequently disrupted graphene sheets. This correlates with IEDFs recorded for the $\mathrm{C} / \mathrm{Ne} / 14 \% \mathrm{~N}_{2}$ plasma consisting mainly of ions exhibiting high energies, which in turn are likely to destroy a structural evolution of the thin films. The assignment of $\mathrm{C} 3$, a minor contribution arising between $403 \mathrm{eV}$ and $402 \mathrm{eV}$, is not consistent in literature. C3 is reported to arise either from N-O (Ref. 11) bonds or due to a similar substitutional bonding configuration as described for $\mathrm{C} 1$, except that the nitrogen donates an electron to the structure; thus, the C3 peak appears at higher binding energies and scales with $\mathrm{C} 1{ }^{11,57} \mathrm{C} 4(\sim 399 \mathrm{eV})$ is assigned to sphybridized nitrogen in a nitrile ${ }^{57}$ structure. Only for $\mathrm{CN}_{\mathrm{x}}$ thin films deposited in Ne-containing atmosphere $\mathrm{C} 4$ could be fitted. This correlates with high amounts of incorporated $\mathrm{N}$ into the film.

Figures 10(a)-10(c) show selected HRTEM images with corresponding SAED patterns from the samples analyzed by XPS and presented in Fig. 9. The comparison of the relative intensities of diffuse SEAD rings provides information about the degree and extension of the graphitic short range order of $\mathrm{CN}_{\mathrm{x}}$ films. ${ }^{41}$ The peak intensity ratio $I_{3.5} \AA / I_{2} \AA(R)$ provides a parameter for the quantitative comparison of the microstructure. The evaluation of SAED pattern revealed $\mathrm{R}$ to be highest $(>1)$ for $\mathrm{CN}_{\mathrm{X}}$ thin films deposited in $\mathrm{Ar}(\mathrm{R} \sim 2)$ and $\mathrm{Kr} \quad(\mathrm{R} \sim 1)$ and $\mathrm{R}<1$ for $\mathrm{CN}_{\mathrm{x}}$ when $\mathrm{Ne}(\mathrm{R} \sim 0)$ was employed as sputter gas. The results extracted from the SAED pattern are also reflected in the corresponding HRTEM images, as these reveal a FL structure for thin films sputtered in Ar- [Fig. 10(b)] or Kr-containing atmosphere [Fig. 10(c)] and an amorphous thin film for the $\mathrm{CN}_{\mathrm{x}}$ thin film produced in $\mathrm{Ne} / \mathrm{N}_{2}$ [Fig. 10(a)].

The relative intensity of the $\sim 3.5 \AA$ peak correlates with the $\mathrm{C} 1 / \mathrm{C} 2$ ratio of the XPS N1s regions as observed for DC sputtered $\mathrm{CN}_{\mathrm{x}}$ films. ${ }^{56}$ However, the correlation is not satisfactory, if merely the XPS $\mathrm{C} 1 / \mathrm{C} 2$ ratio is taken into account, since $\mathrm{CN}_{\mathrm{X}}$ films deposited in $\mathrm{Ar} / 14 \% \mathrm{~N}_{2}$ seem to posses a more pronounced fullerene-like structure by HRTEM and SAED $(\mathrm{R} \sim 2)$ than that deposited in $\mathrm{Kr} / 14 \% \mathrm{~N}_{2}(\mathrm{R} \sim 1)$, although the $\mathrm{C} 1 / \mathrm{C} 2$ ratio for the thin film deposited in $\mathrm{Kr}$ containing atmosphere is higher. Thus, as pointed out above, the peak broadening of $\mathrm{C} 1$ and $\mathrm{C} 2$ as well as the shift of $\mathrm{C} 2$ toward higher binding energies for the $14 \% \mathrm{~N}_{2} / \mathrm{Kr}$ process should also be taken into account, as both are signs of a less ordered structure. ${ }^{57}$
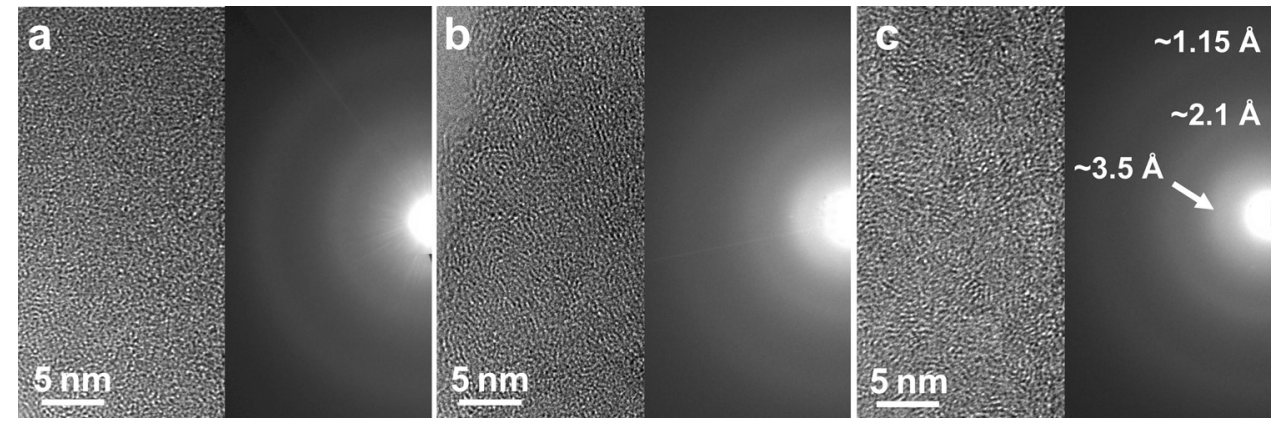

FIG. 10. (a)-(c) Cross-sectional HRTEM images with corresponding SAED patterns from $\mathrm{CN}_{\mathrm{x}}$ thin films deposited by $\mathrm{HiPIMS}$ at $\mathrm{T}_{\mathrm{S}}=430{ }^{\circ} \mathrm{C}$ in $14 \% \mathrm{~N}_{2}$ and different inert gases: (a) $14 \% \mathrm{~N}_{2} / \mathrm{Ne}$, (b) $14 \% \mathrm{~N}_{2} / \mathrm{Ar}$, and (c) $14 \% \mathrm{~N}_{2} / \mathrm{Kr}$. SAED labels in (c) mark the position of $\sim 1.15$ and $\sim 2.1 \AA$ diffuse rings. The arrow indicates the brightest segment of the $\sim 3.5 \AA$ ring, which implies a slightly textured graphitic ordering (with preferred orientation of basal planes perpendicular to the substrate). The growth direction in the HRTEM images shows upwards. The films deposited in Ar and Kr have the most pronounced fullerene-like structure. 


\section{CONCLUSIONS}

Reactive HiPIMS of $\mathrm{C}$ in the inert gases $\mathrm{Ne}, \mathrm{Ar}$, and $\mathrm{Kr}$ yield distinctly different discharges. The I $(\mathrm{t})$ discharge characteristics of the inert gases show increasing target currents with decreasing atomic number, mainly caused by different $I_{P}$ as well as ionization pathways and cross sections. The most abundant precursors in reactive processes are $\mathrm{C}^{+}, \mathrm{N}^{+}$, $\mathrm{N}_{2}{ }^{+}$, single and double charged inert gas ions, and to a lower extent $\mathrm{CN}^{+}$. The IEDFs of the corresponding discharges when no $\mathrm{N}_{2}$ is involved exhibit increasing energies with decreasing atomic number of the inert gas. When the $\mathrm{N}_{2}$ content of the C/Ne-HiPIMS discharge exceeds $14 \%$, the energy of $\mathrm{C}^{+}, \mathrm{Ne}^{+}$, and $\mathrm{N}^{+}$decreases significantly, since Penning ionization of $\mathrm{N}_{2}$ disappears gradually for increasing $\mathrm{N}_{2}$ concentrations in the working gas. When $\mathrm{N}_{2}$ is added to the $\mathrm{Ar}$ and $\mathrm{Kr}$ processes, the energy of the IEDFs increases with increasing $\mathrm{N}_{2}$ content in the sputter gas. However, $\mathrm{Ne}$ - and $\mathrm{Kr}$-containing discharges are more affected by the reactive gas than it is the case for Ar. This can be attributed to much higher differences in $I_{P}$ and the total ionization cross sections for $\mathrm{Ne}$ and $\mathrm{Kr}$ with regards to $\mathrm{N}_{2}$ and $\mathrm{N}$ than for Ar. The total amount of ions increases in the sequence $\mathrm{Kr}$, Ar, and $\mathrm{Ne}$ because of the increasing ionization potential that causes a higher electron temperature of the corresponding plasma and thus, an improved ionization. Additionally, the energy of metastable states increases in the same sequence, which allows only Ne to Penning ionize and excite $\mathrm{N}_{2}$, implicating its highly efficient dissociation. This is mirrored in the amplified abundance of $\mathrm{C}_{\mathrm{x}} \mathrm{N}_{\mathrm{y}}$ species $(\mathrm{x}, \mathrm{y} \leq 2)$ of the Necontaining plasma above $33 \% \mathrm{~N}_{2}$ in the gas. The relative, but not the total $\mathrm{C}^{+}$ion flux is highest in case the graphite target is sputtered in pure Ar, followed by $\mathrm{Ne}$ and $\mathrm{Kr}$. Independent from the inert gas, the relative $\mathrm{C}^{+}$flux decreases in reactive sputter mode and shows a minimum between $33 \%$ and $50 \%$ of $\mathrm{N}_{2}$ in the plasma, in consequence of increasing $\mathrm{N}^{+}$and $\mathrm{N}_{2}{ }^{+}$fluxes. The relative fluxes of $\mathrm{N}^{+}$increase with decreasing atomic number of the inert gas, while the relative flux of $\mathrm{N}_{2}^{+}$shows the opposite trend owing to the increased ability of Ne to dissociate $\mathrm{N}_{2}$. The deposition rates are highest as $\mathrm{C}$ is sputtered in $\mathrm{Kr}$ - or Ar-containing atmosphere, while processes in $\mathrm{Ne}$ yield the lowest deposition rates, which we attribute to back attraction and to physical resputtering due to the high amount and energy of the particles arriving at the substrate. Reactive processes with $14 \% \mathrm{~N}_{2}$ in either $\mathrm{Ne}$ or Ar yield increased deposition rates, whereas similar deposition rates were found for reactive and nonreactive processes involving $\mathrm{Kr}$. The amount of incorporated $\mathrm{N}$ in the $\mathrm{CN}_{\mathrm{x}}$ thin films is highest for Ne-containing processes, which is attributed to a combination of efficient $\mathrm{N}_{2}$ dissociation and ionization, and $\mathrm{N}$ species of high energy that lead to an increased probability for incorporated $\mathrm{N}$ in a pyridineand nitrile-like manner. We also find a relative increase of substitutional bonded nitrogen in a 3 -fold coordinated $\mathrm{C}$ network with atomic number of the inert gas, accounting for a pronounced FL-structure of the thin film. This is also mirrored in TEM and SAED results; amorphous $\mathrm{CN}_{\mathrm{x}}$ thin films were obtained for the process with $\mathrm{Ne} / 14 \% \mathrm{~N}_{2}$, whereas gas mixtures involving $\mathrm{Ar} / 14 \% \mathrm{~N}_{2}$ or $\mathrm{Kr} / 14 \% \mathrm{~N}_{2}$ yielded FL$\mathrm{CN}_{\mathrm{x}}$ thin films. Ion mass spectrometry, XPS, and TEM results emphasize the crucial role of low particle energies generated in the plasma and $\mathrm{N}$-containing precursor species $\left(\mathrm{C}_{\mathrm{x}} \mathrm{N}_{\mathrm{y}}\right)$ for the structural evolution of $\mathrm{CN}_{\mathrm{x}}$ thin films.

\section{ACKNOWLEDGMENTS}

An ERC Advanced Grant and the VINN Excellence Center Functional Nanoscale Materials (FunMat) are acknowledged. With regards to ERDA measurements, the authors are thankful for the access to the Tandem Laboratory, Uppsala University. Zsolt Czigány acknowledges the Bolyai Scholarship of the Hungarian Academy of Sciences.

${ }^{1}$ Y. Lifshitz, Diam. Relat. Mater. 5, 388 (1996).

${ }^{2}$ J. Robertson, Phys. Rev. Lett. 68, 220 (1992).

${ }^{3}$ J. Robertson, Jpn. J. Appl. Phys. 50, 8 (2011).

${ }^{4}$ N. Hellgren, M. P. Johansson, B. Hjorvarsson, E. Broitman, M. Ostblom, B. Liedberg, L. Hultman, and J. E. Sundgren, J. Vac. Sci. Technol. A 18, 2349 (2000).

${ }^{5}$ J. Neidhardt and L. Hultman, J. Vac. Sci. Technol. A 25, 633 (2007).

${ }^{6}$ J. C. Angus and C. C. Hayman, Science 241, 913 (1988).

${ }^{7}$ J. Robertson, Adv. Phys. 35, 317 (1986).

${ }^{8}$ J. Robertson, Mater. Sci. Eng. R 37, 129 (2002).

${ }^{9}$ A. Grill, Diam. Relat. Mater. 12, 166 (2003).

${ }^{10}$ J. Neidhardt, L. Hultman, E. Broitman, T. W. Scharf, and I. L. Singer, Diam. Relat. Mater. 13, 1882 (2004).

${ }^{11}$ L. Hultman, J. Neidhardt, N. Hellgren, H. Sjostrom, and J. E. Sundgren, MRS Bull. 28, 194 (2003).

${ }^{12}$ M. C. Polo, J. L. Andujar, A. Hart, J. Robertson, and W. I. Milne, Diam. Relat. Mater. 9, 663 (2000).

${ }^{13}$ J. Robertson, Prog. Solid State Chem. 21, 199 (1991).

${ }^{14}$ Y. Lifshitz, S. R. Kasi, J. W. Rabalais, and W. Eckstein, Phys. Rev. B 41, 10468 (1990).

${ }^{15}$ P. J. Fallon, V. S. Veerasamy, C. A. Davis, J. Robertson, G. A. J. Amaratunga, W. I. Milne, and J. Koskinen, Phys. Rev. B 48, 4777 (1993).

${ }^{16}$ J. Robertson, Diam. Relat. Mater. 2, 984 (1993).

${ }^{17}$ J. T. Gudmundsson, N. Brenning, D. Lundin, and U. Helmersson, J. Vac. Sci. Technol. A 30, 030801 (2012).

${ }^{18}$ U. Helmersson, M. Lattemann, J. Bohlmark, A. P. Ehiasarian, and J. T. Gudmundsson, Thin Solid Films 513, 124 (2006).

${ }^{19}$ S. Schmidt, Z. Czigany, G. Greczynski, J. Jensen, and L. Hultman, J. Appl. Phys. 112, 013305-11 (2012).

${ }^{20}$ B. M. DeKoven, P. R. Ward, R. E. Weiss, D. J. Christie, R. A. Scholl, W. D. Sproul, F. Tomasel, and A. Anders, in 46th Annual Technical Conference Proceedings, San Francisco, CA (Society of Vacuum Coaters, 2003), pp. 158-165.

${ }^{21}$ K. Sarakinos, A. Braun, C. Zilkens, S. Mraz, J. M. Schneider, H. Zoubos, and P. Patsalas, Surf. Coat. Technol. 206, 2706 (2012).

${ }^{22}$ I. Petrov, L. Ivanov, V. Orlinov, J. Kourtev, and J. Jelev, Thin Solid Films 185, 247 (1990).

${ }^{23}$ A. Aijaz, K. Sarakinos, D. Lundin, N. Brenning, and U. Helmersson, Diam. Relat. Mater. 23, 1 (2012).

${ }^{24}$ K. J. Taylor, S. M. Yun, and G. R. Tynan, J. Vac. Sci. Technol. A 22, 2131 (2004)

${ }^{25}$ K. Ohya, Nucl. Instrum. Meth. Phys. Res. B 206, 52 (2003).

${ }^{26}$ J. C. Avelar-Batista, A. D. Wilson, A. Davison, A. Leyland, A. Matthews, and K. S. Fancey, Thin Solid Films 398-399, 507 (2001).

${ }^{27}$ F. M. Penning and C. C. J. Addink, Physica 1, 1007 (1934).

${ }^{28}$ K. S. Fancey, Vacuum 46, 695 (1995).

${ }^{29}$ J. Nagai, J. C. Thomaz, J. Amorim, and G. Baravian, Eur. Phys. J. 26, 53 (2004).

${ }^{30}$ G. K. Gueorguiev, J. Neidhardt, S. Stafstrom, and L. Hultman, Chem. Phys. Lett. 410, 228 (2005).

${ }^{31}$ M. Schlueter, C. Hopf, and W. Jacob, New J. Phys. 10, 053037 (2008).

${ }^{32}$ J. Bohlmark, M. Lattemann, J. T. Gudmundsson, A. P. Ehiasarian, Y. A. Gonzalvo, N. Brenning, and U. Helmersson, Thin Solid Films 515, 1522 (2006). 
${ }^{33}$ N. Hellgren, M. P. Johansson, E. Broitman, L. Hultman, and J.-E. Sundgren, Phys. Rev. B 59, 5162 (1999).

${ }^{34}$ N. Hellgren, M. P. Johansson, E. Broitman, P. Sandstrom, L. Hultman, and J. E. Sundgren, Thin Solid Films 382, 146 (2001).

${ }^{35}$ H. J. Whitlow, G. Possnert, and C. S. Petersson, Nucl. Instrum. Meth. Phys. Res. B 27, 448 (1987).

${ }^{36}$ J. Jensen, D. Martin, A. Surpi, and T. Kubart, Nucl. Instrum. Meth. Phys. Res. B 268, 1893 (2010).

${ }^{37}$ Z. Czigany, J. Neidhardt, I. F. Brunell, and L. Hultman, Ultramicroscopy 94, 163 (2003).

${ }^{38}$ E. Broitman, N. Hellgren, J. Neidhardt, I. Brunell, and L. Hultman, J. Electron. Mater. 31, L11 (2002).

${ }^{39}$ J. P. McCaffrey, Microsc. Res. Techn. 24, 180 (1993).

${ }^{40}$ J. L. Labar, Microsc. Microanal. 15, 20 (2009).

${ }^{41}$ Z. Czigany and L. Hultman, Ultramicroscopy 110, 815 (2010).

${ }^{42}$ D. Rapp and P. Englander-Golden, J. Chem. Phys. 43, 1464 (1965).

${ }^{43}$ D. M. Mattox, Handbook of Physical Vapor Deposition (PVD) Processing (Noyes, Park Ridge, NJ, 1998).

${ }^{44}$ A. Anders, Surf. Coat. Technol. 205, S1 (2011).

${ }^{45}$ J. T. Gudmundsson, J. Alami, and U. Helmersson, Surf. Coat. Technol. 161, 249 (2002).

${ }^{46}$ A. Hecimovic and A. P. Ehiasarian, IEEE Trans. Plasma Sci. 39, 1154 (2011).
${ }^{47}$ M. Hala, N. Viau, O. Zabeida, J. E. Klemberg-Sapieha, and L. Martinu, J. Appl. Phys. 107, 9 (2010).

${ }^{48}$ G. Lempérière and J. M. Poitevin, Vacuum 37, 825 (1987).

${ }^{49}$ A. Hecimovic, K. Burcalova, and A. P. Ehiasarian, J. Phys. D 41, 10 (2008).

${ }^{50}$ N. Itagaki, S. Iwata, K. Muta, A. Yonesu, S. Kawakami, N. Ishii, and Y. Kawai, Thin Solid Films 435, 259 (2003).

${ }^{51}$ S. Yoon and W. L. Glab, J. Phys. B 27, 4133 (1994).

${ }^{52}$ J. Neidhardt, L. Hultman, B. Abendroth, R. Gago, and W. Moller, J. Appl. Phys. 94, 7059 (2003).

${ }^{53}$ G. Greczynski and L. Hultman, Vacuum 84, 1159 (2010).

${ }^{54}$ N. Brenning, C. Huo, D. Lundin, M. A. Raadu, C. Vitelaru, G. D. Stancu, T. Minea, and U. Helmersson, Plasma Sources Sci. Technol. 21, 025005 (2012).

${ }^{55}$ E. Oyarzabal, R. P. Doerner, M. Shimada, and G. R. Tynan, J. Appl. Phys. 104, 043305 (2008).

${ }^{56}$ J. Neidhardt, L. Hultman, and Z. Czigany, Carbon 42, 2729 (2004).

${ }^{57}$ N. Hellgren, J. H. Guo, Y. Luo, C. Sathe, A. Agui, S. Kashtanov, J. Nordgren, H. Agren, and J. E. Sundgren, Thin Solid Films 471, 19 (2005).

${ }^{58}$ R. Rejoub, B. G. Lindsay, and R. F. Stebbings, Phys. Rev. A 65, 042713 (2002).

${ }^{59}$ Y.-K. Kim and J.-P. Desclaux, Phys. Rev. A 66, 012708 (2002).

${ }^{60}$ J. F. Ziegler, http://www.srim.org/, v. srim 2008 (November 2012). 